\title{
New species and records of Lathrobium from the Palaearctic region, primarily from Nepal (Coleoptera: Staphylinidae: Paederinae)
}

\author{
With 154 figures and 2 maps \\ VOLKER ASSING ${ }^{1}$ \\ ${ }^{1}$ Gabelsbergerstraße 2, 30163 Hannover, Germany. - vassing.hann@t-online.de \\ Published on 2014-07-31
}

\section{Summary}

Eighteen species of Lathrobium Gravenhorst, 1802 from Nepal (16 species) and China (2 species) are described and illustrated: L. semicirculatum sp. n. (E-Nepal; L. nepalense group); L. constrictum sp. n. (E-Nepal; L. discissum group); L. descendens sp. n. (W-Nepal; L. deuvei group); L. ascendens sp. n. (W-Nepal; L. deuvei group); L. rude sp. n. (C-Nepal: Dhaulagiri; L. emodense group); L. latibasale sp. n. (W-Nepal; L. pectinatum group); L. eques sp. n. (W-Nepal; L. pectinatum group); L. equitans sp. n. (C-Nepal: Dhaulagiri; L. pectinatum group); L. abruptum sp. n. (W-Nepal; L. pectinatum group); L. kemum sp. n. (C-Nepal: Dhaulagiri; L. pectinatum group); L. flexaculeatum sp. n. (C-Nepal: Dhaulagiri; L. pectinatum group); L. rectaculeatum sp. n. (C-Nepal: Dhaulagiri; L. pectinatum group); L. curvaculeatum sp. n. (C-Nepal: Dhaulagiri; L. pectinatum group); L. hebes sp. n. (C-Nepal: Dhaulagiri; L. pectinatum group); L. imberbe sp. n. (W-Nepal; L. pectinatum group); L. plicatum sp. n. (C-Nepal: Dhaulagiri; L. pectinatum group); L. glabrimpressum sp. n. (China: Yunnan: Gaoligong Shan; group assignment uncertain); L. smetanai sp. n. (China: Gansu: Dalija Shan; L. lentum group). Based on new material, a redescription and new illustrations of L. aculeatum CoIfFAIT, 1982 are provided. Recently collected material of L. calcaratum AssiNG, 2012 suggests that the holotype of this species may have been mislabelled and that, consequently, the type locality is erroneous. The species previously assigned to the L. aculeatum group are moved to the L. pectinatum group, and the L. aculeatum group is discarded. Several species of the L. pectinatum group were found to be subject to a sexual dimorphism of body size. Additional records of six named species are reported from the West Caucasus (2 species) and from Nepal (4 species). Including the newly described species, the genus is currently represented in the Himalaya by 68 species in ten species groups, in China by 189 species, and in the Palaearctic region by 536 named species and ten subspecies.

\section{Key words}

Coleoptera, Staphylinidae, Paederinae, Lathrobiina, Lathrobium, Palaearctic region, Nepal, China, Caucasus, taxonomy, new species, species groups, sexual size dimorphism, diversity, new records.

\section{Zusammenfassung}

Achtzehn Arten der Gattung Lathrobium Gravenhorst, 1802 aus Nepal (16 Nepal) und China (2 Arten) werden beschrieben und abgebildet: L. semicirculatum sp. n. (Ostnepal; L. nepalense-Gruppe); L. constrictum sp. n. (Ostnepal; L. discissum-Gruppe); L. descendens sp.n. (Westnepal; L. deuvei-Gruppe); L. ascendens sp. n. (Westnepal; L. deuvei-Gruppe); L. rude sp. n. (Zentralnepal: Dhaulagiri; L. emodense-Gruppe); L. latibasale sp. n. (Westnepal; L. pectinatum-Gruppe); L. eques sp. n. (Westnepal; L. pectinatum-Gruppe); L. equitans sp. n. (Zentralnepal: Dhaula- 
giri; L. pectinatum-Gruppe); L. abruptum sp. n. (Westnepal; L. pectinatum-Gruppe); L. kemum sp. n. (Zentralnepal: Dhaulagiri; L. pectinatum-Gruppe); L. flexaculeatum sp. n. (Zentralnepal: Dhaulagiri; L. pectinatum-Gruppe); L. rectaculeatum sp. n. (Zentralnepal: Dhaulagiri; L. pectinatum-Gruppe); L. curvaculeatum sp. n. (Zentralnepal: Dhaulagiri; L. pectinatum-Gruppe); L. hebes sp. n. (Zentralnepal: Dhaulagiri; L. pectinatum-Gruppe); L. imberbe sp. n. (Westnepal; L. pectinatum-Gruppe); L. plicatum sp. n. (Zentralnepal: Dhaulagiri; L. pectinatum-Gruppe); L. glabrimpressum sp. n. (China: Yunnan: Gaoligong Shan; Gruppenzugehörigkeit ungeklärt); L. smetanai sp. n. (China: Gansu: Dalija Shan; L. lentum-Gruppe). Lathrobium aculeatum CoIffart, 1982 wird neu beschrieben und abgebildet. Neues Material von L. calcaratum Assing, 2012 deutet darauf hin, dass der Holotypus dieser Art vermutlich falsch etikettitiert und dass daher auch die Typuslokalität irrtümlich ist. Die bisher der L. aculeatum-Gruppe zugeordneten Arten werden in die L. pectinatum-Gruppe transferiert; die L. aculeatum-Gruppe wird aufgegeben. Die Körpergröße einiger Arten der L. pectinatum- Gruppe ist sexualdimorph. Weitere Nachweise von sechs beschriebenen Arten werden aus dem Westkaukasus (2 Arten) und aus Nepal (4 Arten) gemeldet. Einschließlich der neu beschriebenen Arten ist die Gattung derzeit im Himalaya mit 68 Arten (in zehn Artengruppen), in China mit 189 und in der gesamten Paläarktis mit 536 beschriebenen Arten und zehn Unterarten vertreten.

\section{Introduction}

According to an updated version (SCHÜLKE unpubl.) of the catalogue by SMETANA (2004), including all articles published before 31 October, 2013, the Holarctic genus Lathrobium GRAVENHORST, 1802 was represented in the Palaearctic region by 498 species and 10 subspecies, two nomina dubia not considered. In the meantime, nine additional species have been described, five species have been moved to other genera, and one synonymy has been proposed (Assing 2013d-f). Moreover, seventeen species were described from China very recently by PENG et al. (2014). Thus, with a total of 518 species and 10 subspecies, Lathrobium is by far the most diverse of all genera of Paederinae in the Palaearctic. The diversity hotspots in the East Palaearctic region are China (187 species), followed by Japan (105) species, the Himalaya (52 species), the Russian Far East (46 species), and Taiwan (13 species) (Assing 2010, 2012, 2013e, f; SCHÜLKE unpubl.). According to a recent revision and two supplements (Assing 2012, 2013c, e), the Himalayan species represent eleven species groups, the nepalense (16 species), muguicum (2), emodense (4), excisum (1), deuvei (8), gladiator (1), discissum (2), jumlense (4), uttaricum (1), aculeatum (2), and pectinatum (11) groups.

The present study is based primarily on previously unrevised material from the collections of the Naturkundemuseum Erfurt, which included a remarkable number of undescribed species, particularly from the Dhaulagiri range in Central Nepal, as well as from West Nepal. Some additional specimens were made available by Aleš Smetana (Ottawa) and Guillaume de Rougemont (Oxford).

\section{Material and methods}

The material treated in this study is deposited in the following public institutions and private collections:

\section{CAS Chinese Academy of Sciences, Beijing \\ NME Naturkundemuseum Erfurt (M. Hartmann) \\ cAss author's private collection \\ cRou private collection Guillaume de Rougemont, Oxford \\ cSme private collection Aleš Smetana, Ottawa}

The morphological studies were conducted using a Stemi SV 11 microscope (Zeiss Germany) and a Jenalab compound microscope (Carl Zeiss Jena). A digital camera (Nikon Coolpix 995) was used for the photographs. The maps were created using MapCreator 2.0 (primap) software.

Body length was measured from the anterior margin of the mandibles (in resting position) to the abdominal apex, the length of the forebody from the anterior margin of the mandibles to the posterior margin of the elytra, head length from the anterior margin of the frons to the posterior margin of the head, elytral length at the suture from the apex of the scutellum to the posterior margin of the elytra (at the suture), and the length of the aedeagus from the apex of the ventral process to the base of the aedeagal capsule. The "parameral" side (i.e., the side where the sperm duct enters) is referred to as the ventral, the opposite side as the dorsal aspect.

\section{Descriptions and additional records}

\subsection{Species from the West Palaearctic region}

\section{Lathrobium eppelsheimii CzWALINA, 1888}

Material examined: Russia: 27 exs., West Caucasus, Krasnodar region, Guama near Mezmai, 1000 m, 10.VI.1999, leg. Smetana [R7] (cSme, cAss); 21 exs., Krasnodar region, Guama near Mezmai, 950-1000 m, 11.VI.1999, 
leg. Smetana [R8] (cSme, cAss); 1 ex., Krasnodar region, Temnolesskaia near Mezmai, 750 m, 12.VI.1999, leg. Smetana [R9] (cSme); 33 exs., same data, but 7.VI.1999 [R2] (cSme, cAss); 9 exs., same data, but 800 m, 8.VI.1999 [R3]; 1 ex., same data, but $850 \mathrm{~m}, 8 . \mathrm{VI} .1999$ [R4] (cSme); 5 exs., same data, but 850 m, 9.VI.1999 [R5-6] (cSme); 7 exs., same data, but 850 m, 19.VI.1999 [R18] (cSme, cAss); 7 exs., Krasnodar region, Mezmai, 800 m, 18.VI.1999, leg. Smetana [R17] (cSme, cAss).

Comment: The distribution of the micropterous L. eppelsheimii is confined to the Northwest Caucasus. The above material suggests that it is rather common, at least in some regions of its range. It was collected by sifting leaf litter and other debris in various types of forest (open oak forest, beech forest, fir forest, mixed beech and fir forests) at altitudes of 750-1000 m (SMETANA pers. comm.). For a detailed redescription, illustrations, a distribution map, and additional details see SoloDOVNIKOV (2001).

\section{Lathrobium tichomirovae CoIFFAIT, 1981}

Material examined: Russia: $1 \sigma^{\star}$, West Caucasus, Adygea, Lagonaki Plateau, $12 \mathrm{~km}$ NE Mt. Fisht, $1850 \mathrm{~m}$, sifting debris along edges of a snowfield, 14.VI.1999, leg. Smetana [R12] (cAss).

Comment: The original description of L. tichomirovae is based on a male holotype from Maykop (West Caucasus: Adygea) and two paratypes from the Talysh mountains (East Caucasus) (CoIfFAIT 1981). A comparison of material of this species from various regions in the Caucaus revealed that the basal portion of the ventral process is apparently highly variable and that the extreme conditions seem to be linked by transitional conditions. If more thorough studies should reveal that this variation is indeed of an intraspecific nature, L. tichomirovae will eventually have to be synonymized with L. bernhaueri KocH, 1937 (type locality: "Caucasus").

\subsection{Species from Nepal}

\section{Lathrobium semicirculatum sp. $\mathrm{n}$. (Figs 1-9, Map 1)}

Type material: Holotype $\sigma^{*}$ : "NEPAL, Mechi/Taplejung, 17,5 km NE Ghunsa, Lhonak, $4770 \mathrm{~m}, 27^{\circ} 47^{\prime} 27^{\prime \prime} \mathrm{N}$, $88^{\circ} 02^{\prime} 12 " E, 12$.V.2003, leg. A. Weigel / Holotypus o Lathrobium semicirculatum sp. n., det. V. Assing 2013” (NME). Paratypes: 1 o : same data as holotype (cAss); $20^{*} o^{*}$ : "NEPAL Yalungi, Taplejung 3500 m, V.1989 P. Morvan" (cRou, cAss).

Etymology: The specific epithet (Latin, adjective: semicircular) refers to the shape of the posterior excision of the male sternite VIII.
Description: Body length 6.0-7.6 mm; length of forebody 3.0-3.2 mm. Habitus as in Fig. 1. Coloration: body blackish; legs dark-brown; antennae reddish to dark-brown. Head (Fig. 2) weakly oblong, 1.02-1.04 times as long as broad; punctation sparse and moderately coarse; interstices much broader than diameter of punctures, with fine but distinct microreticulation. Eyes moderately small, composed of approximately 30-40 ommatidia, one-fourth to one-third as long as postocular region in dorsal view. Antenna approximately $1.7 \mathrm{~mm}$ long.

Pronotum (Fig. 2) approximately 1.15 times as long as broad and 1.04-1.10 times as broad as head; punctation similar to that of head, but denser; midline moderately broadly impunctate; interstices without microsculpture. Elytra (Fig. 2) rather broad, transverse, and short, approximately 0.53 times as long as pronotum; punctation fine and shallow; interstices without distinct microsculpture. Hind wings completely reduced. Protarsomeres I-IV with weakly pronounced sexual dimorphism.

Abdomen approximately 1.15 times as broad as elytra; punctation fine and moderately dense; microsculpture shallow on tergites III-VI, somewhat more pronounced on tergites VII-VIII; posterior margin of tergite VII without palisade fringe; tergite VIII with weakly convex posterior margin, without distinct sexual dimorphism. $\sigma^{*}$ : protarsomeres I-IV moderately dilated; sternite VII (Fig. 3) strongly transverse, with relatively sparse unmodified setae, middle narrowly without setae, posterior margin broadly concave; sternite VIII (Fig. 4) weakly transverse, approximately 1.07 times as broad as long, in postero-median portion (anterior to postero-median excision) with dense and rather short setae, otherwise with relatively sparse unmodified setae, posterior excision weakly asymmetric, of nearly semi-circular shape; aedeagus (Figs 5-7) approximately $1.25 \mathrm{~mm}$ long, slender, and strongly curved in lateral view, weakly asymmetric in ventral view; ventral process with pronounced long median carina; dorsal plate lamellate, distinctly sclerotized, with long apical portion and short basal portion; internal sac with long dark membranous structures.

q : protarsomeres I-IV moderately dilated, slightly less so than in male; sternite VIII (Fig. 8) approximately as long as broad, posterior margin broadly convex, indistinctly angled in the middle; tergite IX (Fig. 9) undivided in the middle, postero-lateral processes short, only slightly extending beyond apex of tergite X; tergite X (Fig. 9) flat, of oval shape, and approximately as long as anteromedian portion of tergite IX.

Comparative notes: Based on the external and sexual characters, L. semicirculatum belongs to the L. nepalense group. Among the species of this group it is characterized particularly by the shape and chaetotaxy of the male sternite VIII, as well as by the distinctive morphology of the aedeagus. The latter is most similar to that of $L$. infractum Assing, 2012, from which L. semicirculatum differs by the sparser pubescence of the male sternite VII, the chaetotaxy and the pronounced posterior excision of 


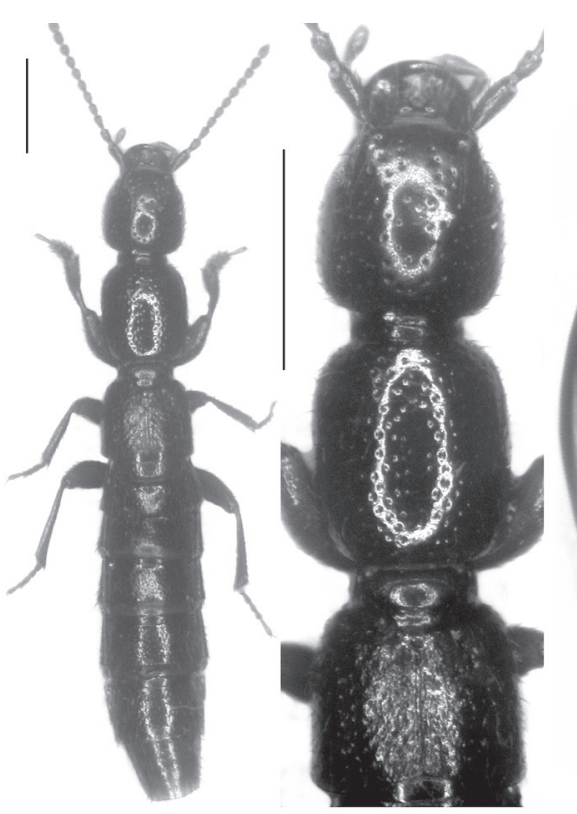

1

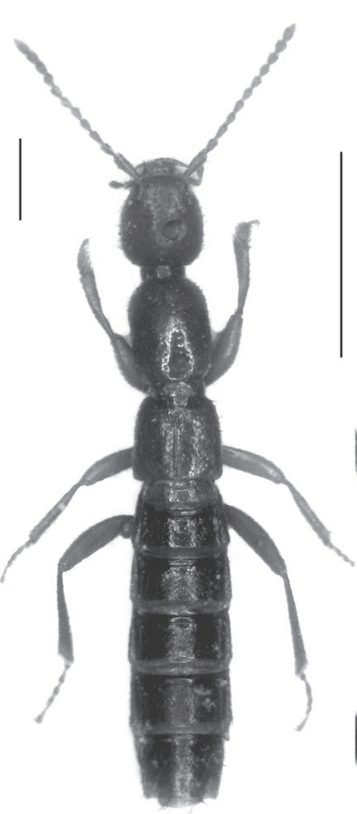

10

2

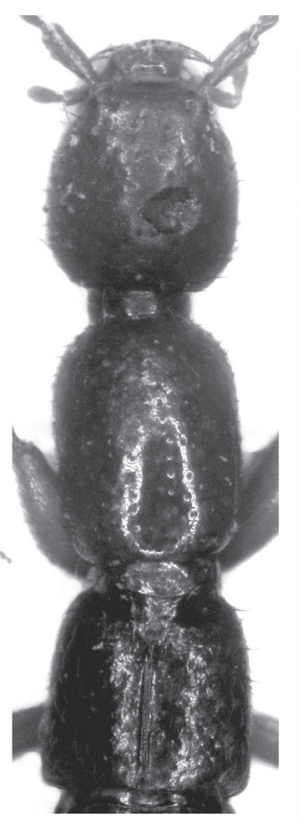

11

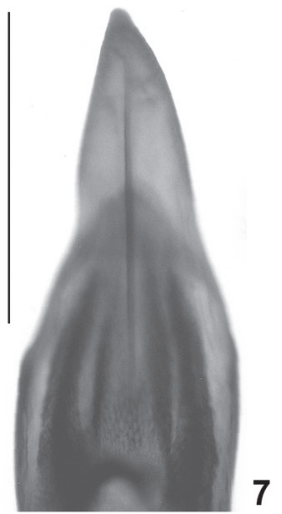

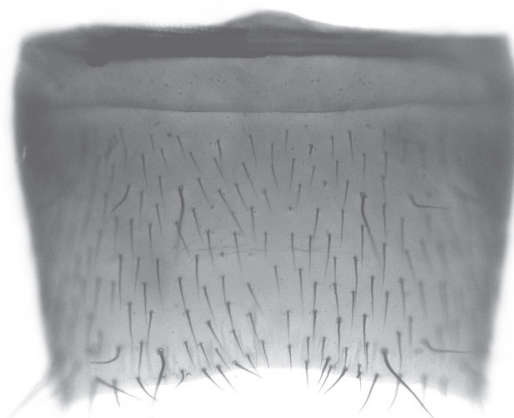

12

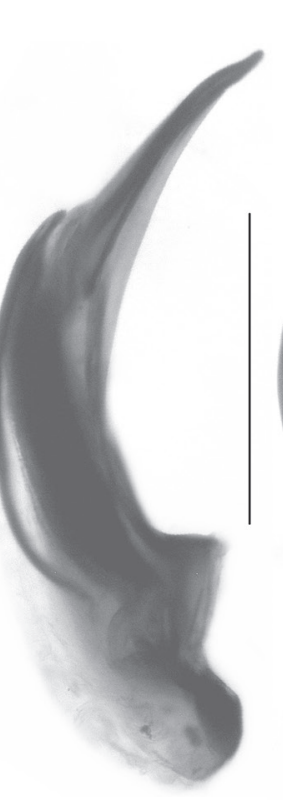

5

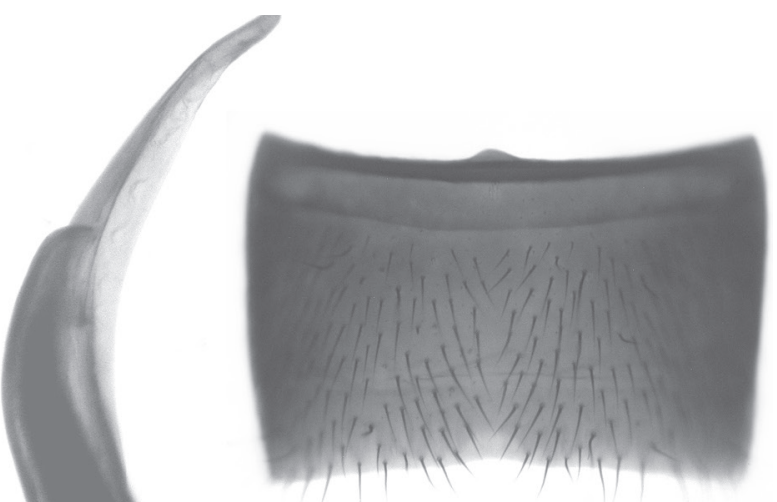

3

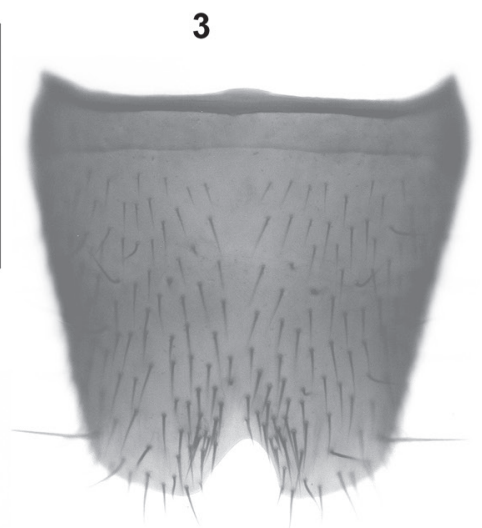

4

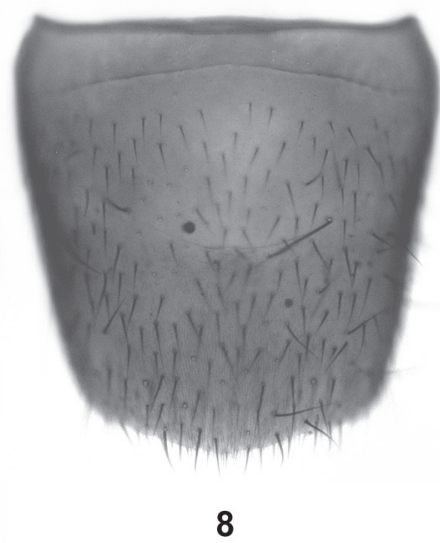

15

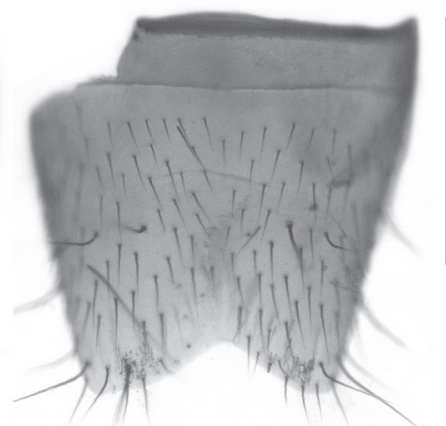

13

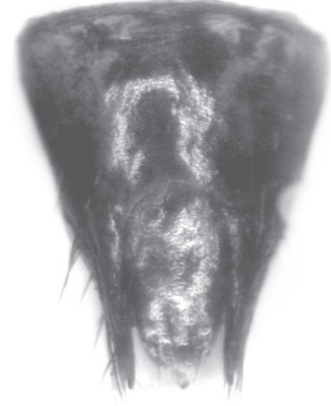

9

Figs 1-15: Lathrobium semicirculatum sp. n. (1-9) and L. constrictum sp. n. (10-15): habitus (1, 10); forebody (2, 11); male sternite VII $(3,12)$; male sternite VIII $(4,13)$; aedeagus in lateral and in ventral view $(5-6,14-15)$; apical portion of aedeagus in ventral view (7); female sternite VIII (8); female tergites IX-X (9). Scale bars: 1-2, 10-11: $1.0 \mathrm{~mm}$; 3-9, 12-15: 0.5 mm. 


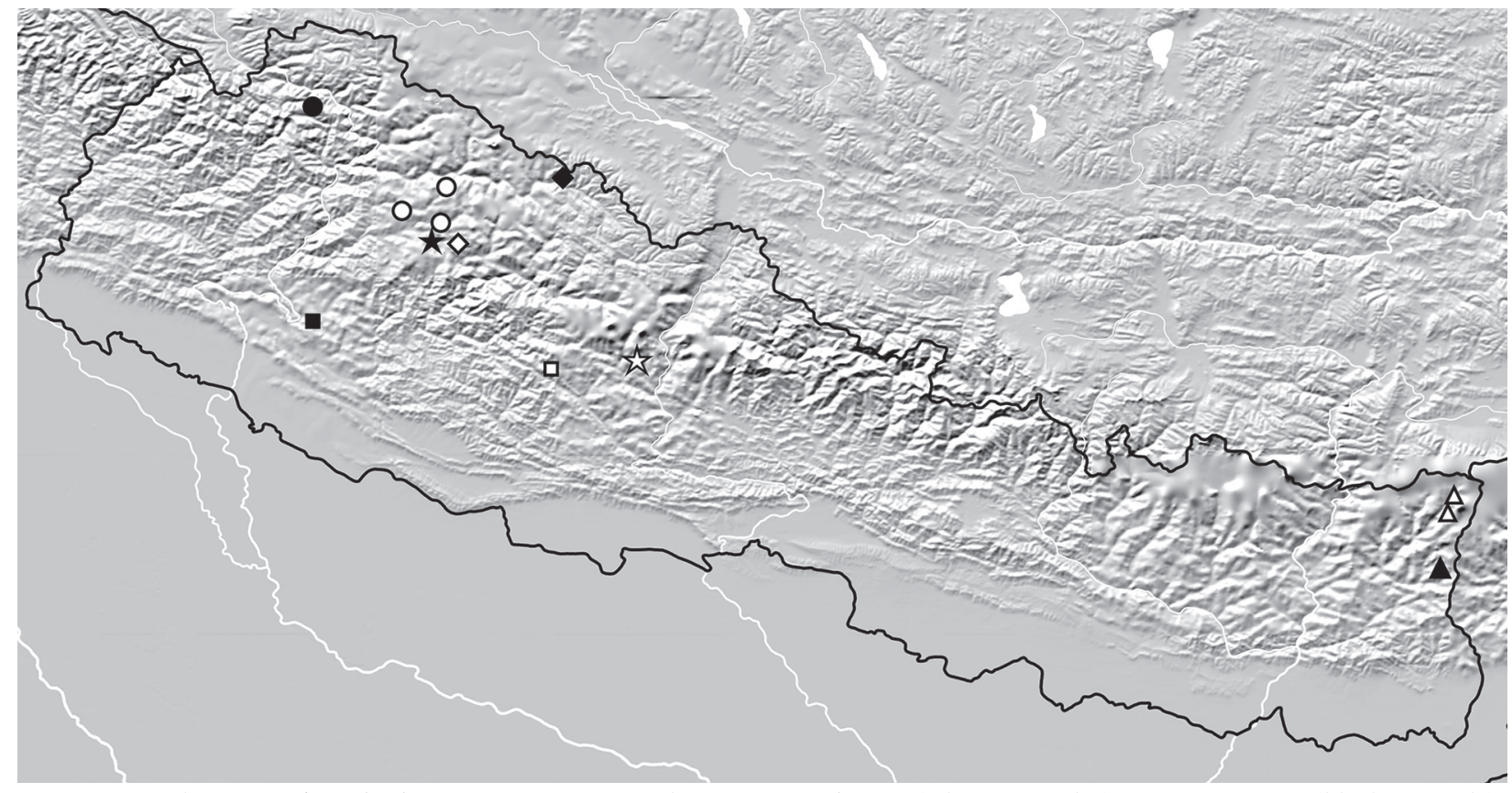

Map 1: Distributions of Lathrobium species in Nepal: L. semicirculatum (white triangles), L. constrictum (black triangle), L. descendens (white circles), L. ascendens (black circle), L. rude (white star), L. latibasale (black star), L. eques (white diamond), L. equitans (black diamond), L. abruptum (black square), L. kemum (white square).

the male sternite VIII (absent in L. infractum), and by the distinctly longer, more slender, and less asymmetric aedeagus. For illustrations of other species of the L. nepalense group see Assing (2012).

Distribution and natural history: The species was collected in two localities (Map 1) in the extreme northeast of Nepal (Taplejung province and border between Taplejung and Mechi provinces), one of them to the northeast of Ghunsa and the other near the Yalung Glacier $\left(27^{\circ} 37^{\prime} \mathrm{N}, 88^{\circ} 04^{\prime} \mathrm{E}\right)$, at altitudes of 4770 and $3500 \mathrm{~m}$, respectively.

\section{Lathrobium constrictum sp. n.}

(Figs 10-15, Map 1)

Type material: Holotype ${ }^{\top}$ [dissected prior to present study]: "NEPAL $3000 \mathrm{~m}$. Kali Danda Massif, V.1989 P. Morvan / L. alticola Coiff.?, det. 198 [sic], G. de Rougemont / Holotypus o Lathrobium constrictum sp. n., det. V. Assing 2013" (cRou).

Etymology: The specific epithet (Latin, adjective) alludes to the subapically distinctly constricted ventral process of the aedeagus.

Description: Slender species; body length $7.8 \mathrm{~mm}$; length of forebody $3.7 \mathrm{~mm}$. Habitus as in Fig. 10. Coloration: head and pronotum reddish; elytra reddish-brown; abdomen dark-brown; legs and antennae reddish.

Head (Fig. 11) 1.08 times as long as broad; punctation sparse and moderately coarse; interstices much broader than diameter of punctures, with fine and distinct microreticulation. Eyes moderately small, composed of approximately 30 ommatidia, approximately one-fourth as long as postocular region in dorsal view. Antenna $2.2 \mathrm{~mm}$ long.

Pronotum (Fig. 11) slender, 1.33 times as long as broad and 0.97 times as broad as head; punctation similar to that of head; midline broadly impunctate; interstices without microsculpture.

Elytra (Fig. 11) 0.57 times as long as pronotum; punctation fine and shallow; interstices without distinct microsculpture; suture gaping posteriorly. Hind wings completely reduced.

Abdomen approximately 1.15 times as broad as elytra; punctation fine and moderately dense; interstices with fine transverse microsculpture; posterior margin of tergite VII without palisade fringe; tergite VIII with weakly convex posterior margin.

$0^{\top}$ : protarsomeres I-IV moderately dilated; sternite VII (Fig. 12) moderately transverse, with relatively sparse unmodified pubescence, posterior margin broadly concave; sternite VIII (Fig. 13) weakly transverse, with unmodified pubescence, posterior excision very broadly V-shaped; aedeagus (Figs 14-15) approximately $1.1 \mathrm{~mm}$ long, slender, and symmetric; ventral process nearly straight in lateral view and conspicuously constricted subapically in ventral view; dorsal plate reduced, not sclerotized; internal sac with long membranous structure.

q: unknown.

Comparative notes: As can be inferred from the external (slender habitus) and the male sexual characters (sternite VIII with unmodified pubescence and with broad and shallow posterior excision; aedeagus slender, symmetric, without sclerotized dorsal plate, and with 
long membranous structure in internal sac), L. constrictum belongs to the L. discissum group. This group previously included two species from Darjeeling (India: West Bengal) and the extreme east of Nepal: L. discissum Assing, 2012 and L. separatum Assing, 2012. From both species, L. constrictum differs by the conspicuous shape of the ventral process of the aedeagus (ventral view). It is additionally distinguished from $L$. discissum by the less transverse sternite VII with sparser pubescence and a differently shaped posterior margin, as well as by the more sparsely pubescent male sternite VIII, and from $L$. separatum by distinctly larger body size (L. separatum: length of forebody $2.7-3.0 \mathrm{~mm}$ ). For illustrations of the previously described species of the L. discissum group see Assing (2012).

Distribution and natural history: The type locality is situated in the Kali Danda (Map 1), a mountain range to the west of the Singalila range and to the south of the Kangchenjunga Himal in Taplejung District (ca. $25 \mathrm{~km}$ E Taplejung; approximately $27^{\circ} 22.5^{\prime} \mathrm{N}, 87^{\circ} 55-58^{\prime} \mathrm{E}$ ). The holotype was collected at an altitude of $3000 \mathrm{~m}$.

\section{Lathrobium descendens sp. $\mathrm{n}$. (Figs 16-24, Map 1)}

Type material: Holotype $\sigma^{*}$ : "NEPAL, Prov. Karnali, distr. Jumla, N Khari Lagna, Bachtal, Ufer, 3280 m NN, $29^{\circ} 22,14^{\prime} \mathrm{N}, 82^{\circ} 09,17^{\prime} \mathrm{E}, 21 . \mathrm{VI} .1999$, leg. M. Hartmann / Holotypus ơ Lathrobium descendens sp. n., det. V. Assing 2013" (NME).

Paratypes: $10^{\star}, 5$ 우 + : same data as holotype (NME, cAss); $10^{\top}$ : "NEPAL oc. Karnali Prov., 34 km NE Jumla, Bachtal SE Taka, 29³0'12"N, 82²4'20"E, 3800 m, 01.VII.1999 leg. A. Weigel” (cAss); 1 \%: "NEPAL oc. Prov. Karnali Distr. Jumla, 15 km N Talphi Dhauli Lake 28.VI.1997 SF, HF, $4400 \mathrm{~m}$ leg. A. Weigel” (NME).

Etymology: The specific epithet is the present participle of the Latin verb descendere (to climb down). It alludes to fact that this is the first species of the L. deuvei group to be recorded from elevations below $4000 \mathrm{~m}$.

Description: Body length 5.4-6.3 mm; length of forebody 3.0-3.2 mm. Body slender and somewhat flattened; habitus as in Fig. 16. Coloration: whole body, including the appendages, reddish.

Head (Fig. 17) 1.02-1.08 times as long as broad, weakly convex in cross section; punctation rather dense and moderately coarse; interstices on average approximately as broad as diameter of punctures, with shallow microreticulation. Eyes reduced to minute narrowly oblong rudiments without pigmentation and with approximately 5 ommatidia. Antenna long and slender, $1.9-2.1 \mathrm{~mm}$ long.

Pronotum (Fig. 17) weakly convex in cross-section and conspicuously slender, 1.4 times as long as broad and 0.80-0.85 times as broad as head, widest anteriorly; lateral margins very weakly converging posteriorly and nearly straight in dorsal view; punctation similar to that of head; midline moderately broadly impunctate; interstices without microsculpture.

Elytra (Fig. 17) slender, approximately 0.62 times as long as pronotum, combined width only approximately 1.3 times the length of suture; humeral angles completely obsolete; suture gaping posteriorly; punctation very shallow and ill-defined; interstices without distinct microsculpture. Hind wings completely reduced. Protarsomeres I-IV without appreciable sexual dimorphism, weakly dilated in both sexes.

Abdomen approximately 1.15 times as broad as elytra; punctation fine and dense; interstices with shallow microsculpture; posterior margin of tergite VII without palisade fringe; posterior margin of tergite VIII truncate to weakly convex in both sexes.

$\sigma^{*}$ : sternite VII (Fig. 18) strongly transverse and with unmodified pubescence, posterior margin broadly concave, in the middle weakly convex; sternite VIII (Fig. 19) transverse, approximately 1.25 times as broad as long, in the middle with narrow band without pubescence, posterior excision approximately 0.2 times as deep as length of sternite; aedeagus (Figs 20-22) 0.73$0.77 \mathrm{~mm}$ long; dorsal plate with very long, distinctly sclerotized, and apically hooked apical portion, and with short membranous basal portion; internal sac with a pair of apically acute, weakly sclerotized apical structures.

+ : sternite VIII (Fig. 23) approximately as long as broad and with convex posterior margin; tergite IX (Fig. 24) undivided in the middle, postero-lateral processes apically acute and rather short, but distinctly extending beyond apex of tergite X; tergite X (Fig. 24) weakly convex in cross-section, of oval shape, and slightly shorter than antero-median portion of tergite IX.

Intraspecific variation: The aedeagus of the male from the locality to the southeast of Taka (Fig. 20) is distinguished from those of the males from the type locality (Fig. 21) by a slightly different shape of the ventral process (lateral view). However, since no additional characters were found suggesting that the specimens from the two localities should represent distinct species, this difference is attributed to intra- rather than interspecific variation.

Comparative notes: Based on the external (slender habitus with long legs and antennae; flattened body; eyes reduced to minute rudiments; relatively long and slender elytra) and the male sexual characters (strongly transverse male sternite VII; aedeagus slender; dorsal plate with long, distinctly sclerotized, and apically hooked apical portion; presence of pairs of apical internal structures), L. descendens undoubtedly belongs to the L. deuvei group, which is distributed in West and Central Nepal (Assing 2012). From the previously described species of this group, L. descendens is readily distinguished by its distinctly smaller size, by the posteriorly less strongly excavate male sternite VII, the much smaller and narrower posterior 

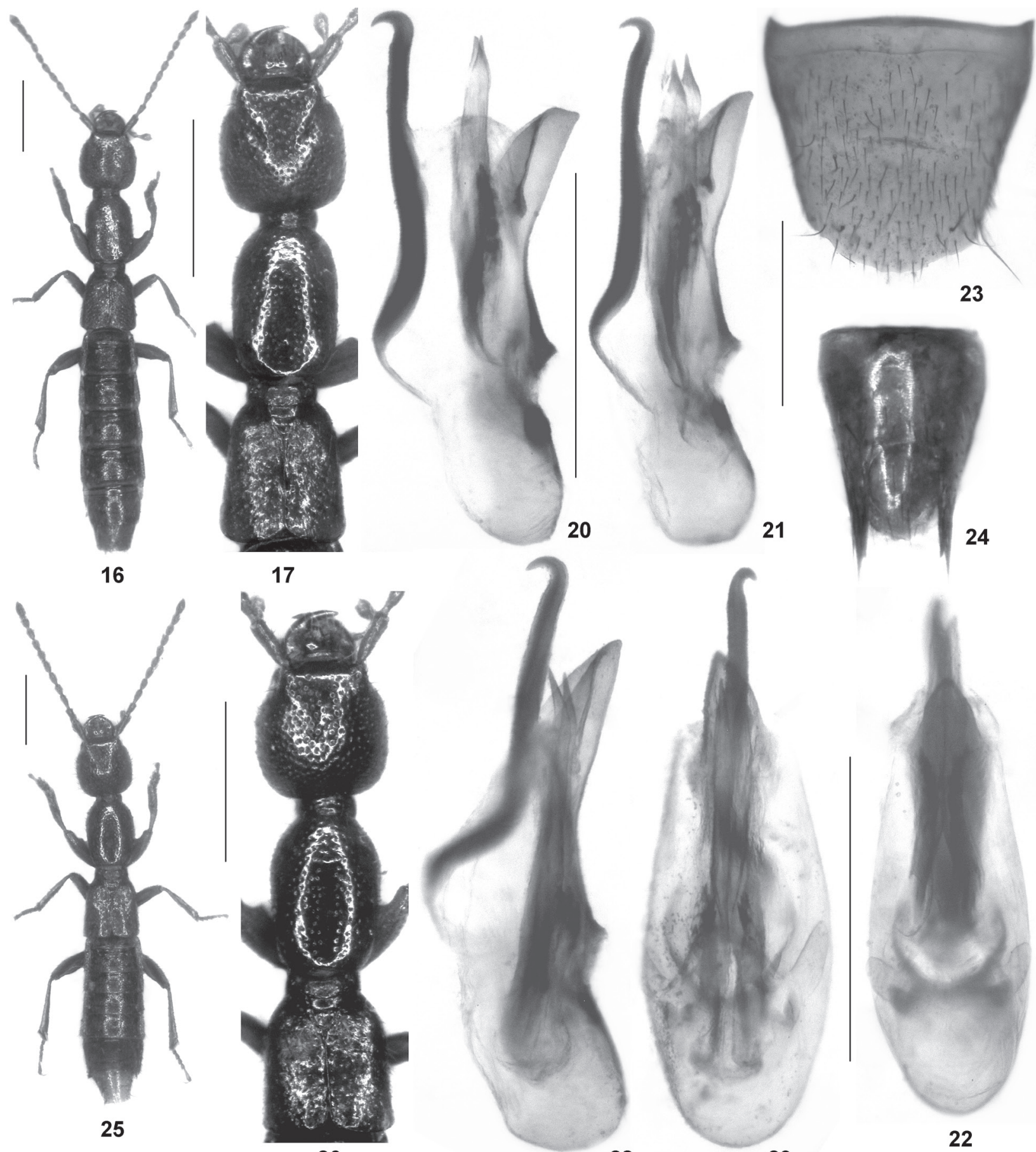

26

28

29
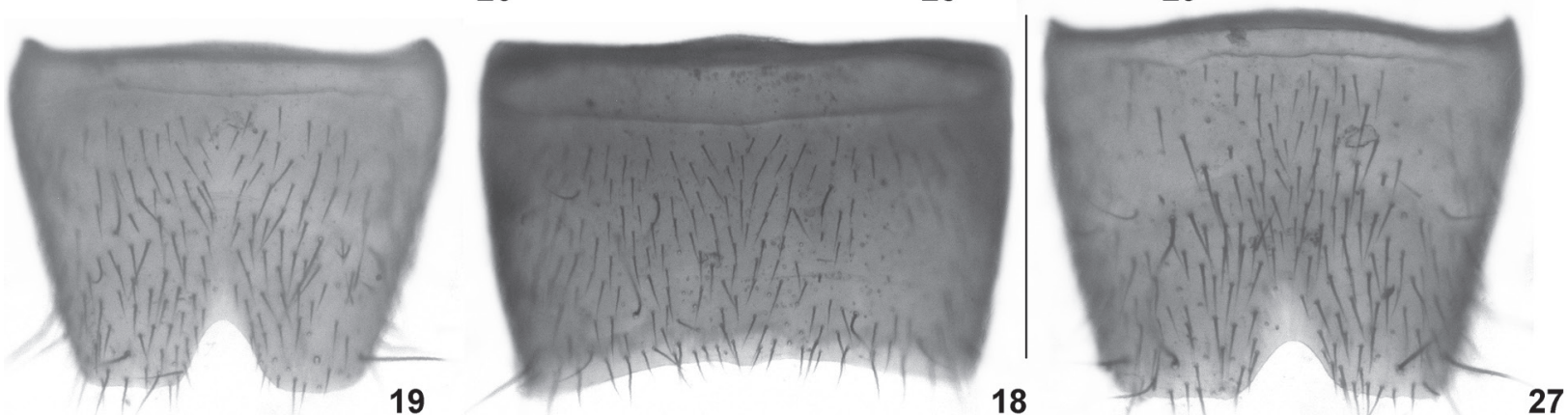

Figs 16-29: Lathrobium descendens sp. n. (16-24) and L. ascendens sp. n. (25-29): habitus (16, 25); forebody (17, 26); male sternite VII (18); male sternite VIII (19, 27); aedeagus in lateral and in ventral view (20-22, 28-29); female sternite VIII (23); female tergites IX-X (24). Scale bars: 16-17, 25-26: $1.0 \mathrm{~mm}$; 18-24, 27-29: $0.5 \mathrm{~mm}$. 
excision of the male sternite VII, as well as by the shape of the smaller aedeagus. It is separated from L. barthei CoIfFAIT 1987, the sole previously known representative of the L. deuvei group recorded from West Nepal, by much smaller size alone (L. barthei: body length $8.2 \mathrm{~mm}$; length of forebody $4.3 \mathrm{~mm}$ ). For illustrations of the previously described representatives of the $L$. deuvei group see Assing (2012).

Distribution and natural history: The species was found in three localities in Jumla District, West Nepal (Map 1), at altitudes of 3280-4400 m. The only record from above $3800 \mathrm{~m}$, however, is based on a female and requires confirmation. The previously described species of the L. deuvei group were recorded at elevations between 4100 and $5200 \mathrm{~m}$.

\section{Lathrobium ascendens sp. $\mathrm{n}$.}

(Figs 25-29, 45, 138-139, Map 1)

Type material: Holotype $0^{\star}:$ "NEPAL Karnali/Humla, $16 \mathrm{~km} \mathrm{~W} \mathrm{Simikot,} 3 \mathrm{~km}$ NW Sankha-La 47-4800 m, $29^{\circ} 56^{\prime} 39^{\prime \prime} \mathrm{N}, 81^{\circ} 39^{\prime} 02^{\prime \prime E}, 30 . V I .2001$ leg. A. Weigel / Holotypus $0^{\star}$ Lathrobium ascendens sp. n., det. V. Assing 2013" (NME).

Paratype i : same data as holotype (cAss).

Etymology: The specific epithet is the present participle of the Latin verb ascendere (to climb up). It alludes to the high altitude of the type locality.

Description: Body length 5.3-5.8 mm; length of forebody 3.1-3.3 mm. Body slender and somewhat flattened; habitus as in Fig. 25. Coloration: body reddish, with the elytra reddish-yellow; legs dark-yellowish; antennae palereddish.

Head (Fig. 26) 1.02-1.06 times as long as broad, weakly convex in cross-section; punctation dense and rather coarse; interstices on average narrower than diameter of punctures, with shallow microreticulation. Eyes reduced to minute subcircular rudiments without pigmentation and with approximately 10 ommatidia. Antenna long and slender, $2.1 \mathrm{~mm}$ long.

Pronotum (Fig. 26) weakly convex in cross-section and conspicuously slender, 1.4 times as long as broad and 0.84 times as broad as head, widest anteriorly; lateral margins distinctly converging posteriorly and somewhat convex in dorsal view; punctation sparser and somewhat less coarse than that of head; midline rather narrowly impunctate; interstices without microsculpture.

Elytra (Fig. 26) slender, 0.61-0.64 times as long as pronotum, combined width $1.28-1.36$ times the length of suture; humeral angles nearly completely obsolete; suture gaping posteriorly; punctation very shallow and ill-defined; interstices without distinct microsculpture. Hind wings completely reduced. Protarsomeres I-IV with weakly pronounced sexual dimorphism.
Abdomen approximately 1.15 times as broad as elytra; punctation fine and dense; interstices with shallow microsculpture; posterior margin of tergite VII without palisade fringe; posterior margin of tergite VIII weakly convex.

$\sigma^{\top}$ : protarsomeres I-IV moderately dilated; sternite VII (Fig. 138) strongly transverse and with unmodified pubescence, posterior margin broadly and weakly concave, in the middle weakly convex; sternite VIII (Fig. 27) transverse, approximately 1.2 times as broad as long, posterior excision rather broad and not very deep, 0.15 times as deep as length of sternite; aedeagus (Figs 28-29) $0.85 \mathrm{~mm}$ long; dorsal plate with very long, distinctly sclerotized, and apically hooked apical portion, and with short membranous basal portion; internal sac with a pair of long, moderately sclerotized, and apically acute structures.

o : protarsomeres I-IV slightly less distinctly dilated than in male; sternite VIII (Fig. 139) weakly transverse, 1.08 times as broad as long, posterior margin rather weakly convex and in the middle weakly concave; tergite IX (Fig. 45) undivided in the middle, posterolateral processes apically acute and rather short, but distinctly extending beyond apex of tergite $\mathrm{X}$; tergite $\mathrm{X}$ (Fig. 45) distinctly convex in cross-section, of oval shape, and noticeably shorter than antero-median portion of tergite IX.

Comparative notes: As can be inferred from the highly similar external and sexual characters, L. ascendens is closely allied to L. descendens, from which it differs particularly by the coarse and denser punctation of the head, the larger and subcircular eye rudiments with more ommatidia, the slightly different shape of the pronotum, the slightly different chaetotaxy of the male sternite VIII, the less deep posterior excision of the male sternite VIII, the larger aedeagus with a differently shaped ventral process and with longer and more strongly sclerotized internal spines, and by the less slender and differently shaped female sternite VIII.

Distribution and natural history: The type locality is situated in Humla District, West Nepal (Map 1), at an altitude of $4700-4800 \mathrm{~m}$.

\section{Lathrobium rude sp. n. \\ (Figs 30-35, Map 1)}

Type material: Holotype $0^{*}$ : "NEPAL, S slope Dhaulagiri Mts. NE slope Asnam Duri, 3100-3300 m, 28³1'50"N, $83^{\circ} 27^{\prime} 57^{\prime \prime E}$, 14.V.2009, leg. J. Schmidt / Holotypus o Lathrobium rude sp. n., det. V. Assing 2013" (NME).

Etymology: The specific epithet (Latin, adjective: raw, crude) alludes to the practically unmodified male sternite VII. 


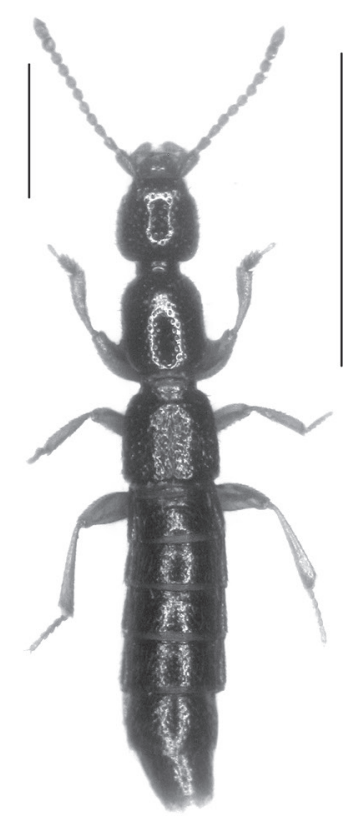

30

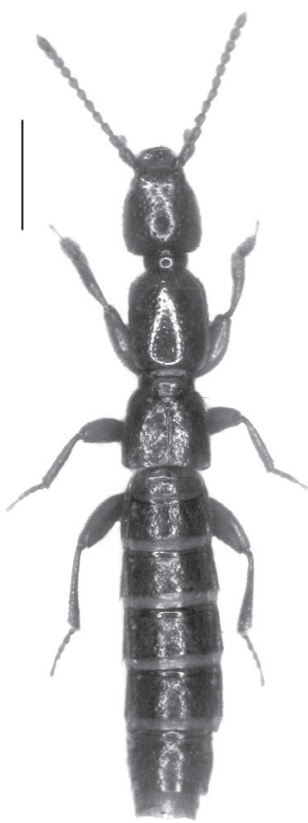

36

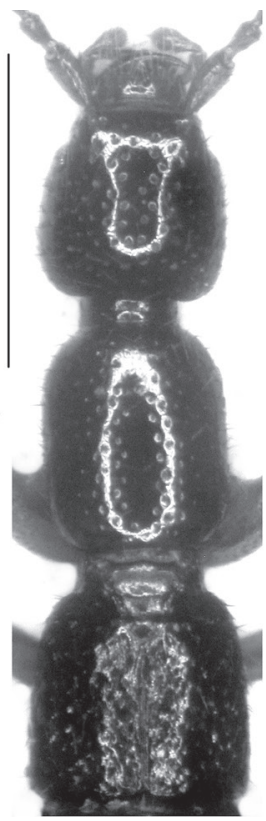

31

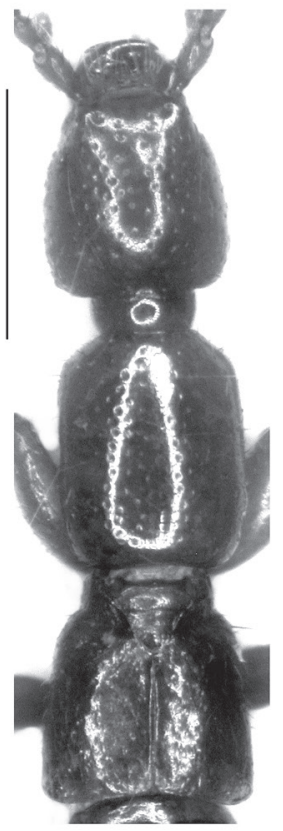

37

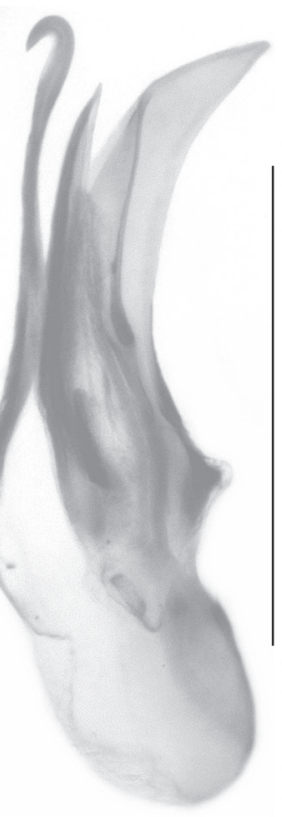

34

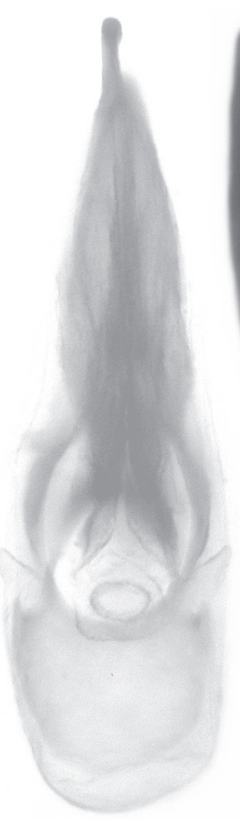

35

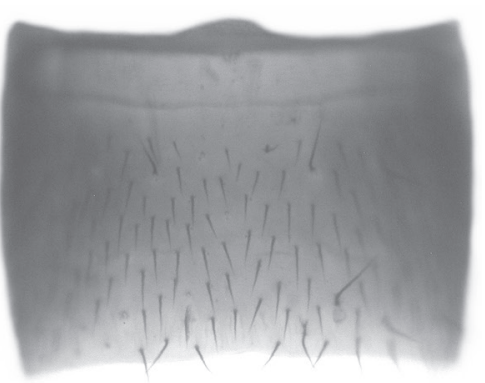

32

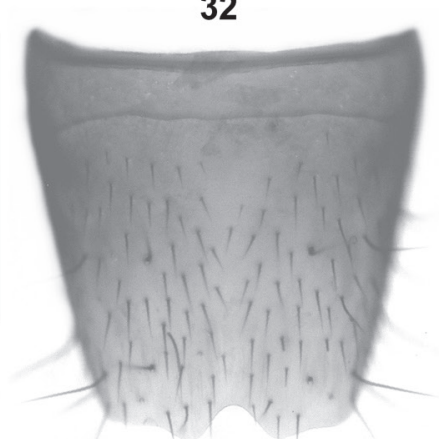

33

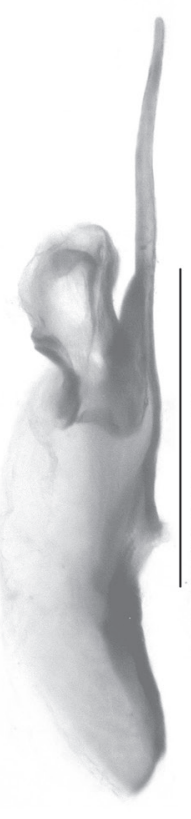

41

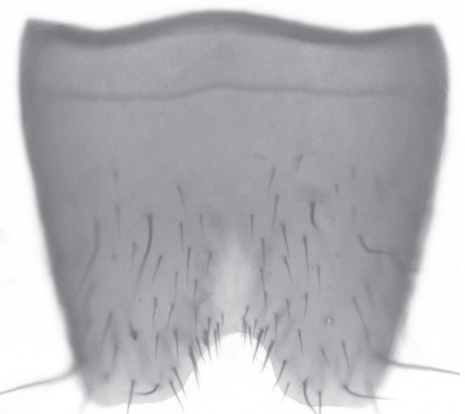

40

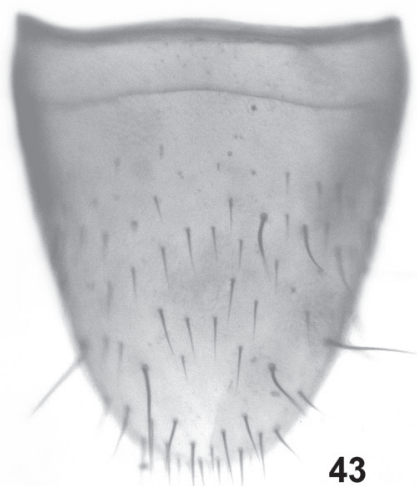

42

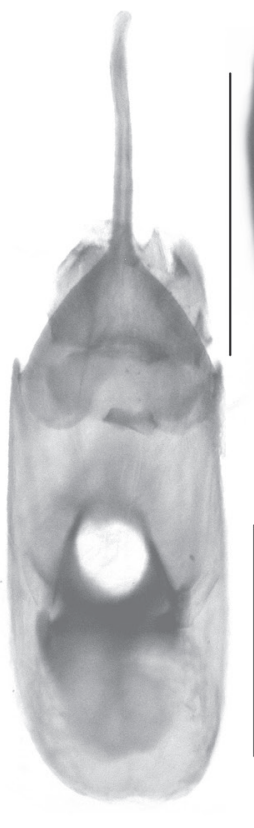

42

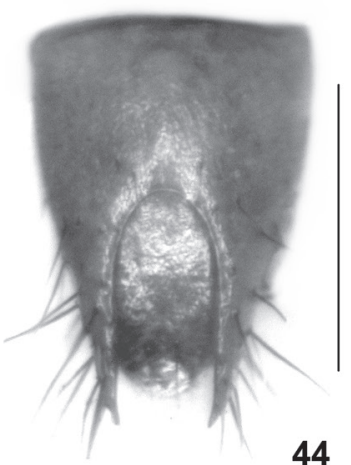

39

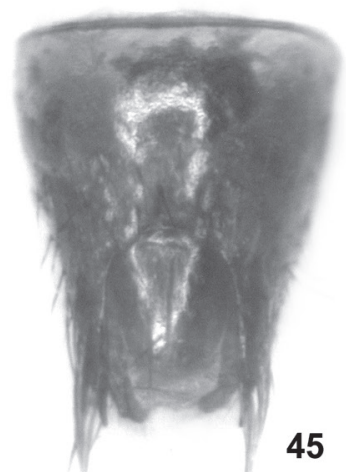

Figs 30-45: Lathrobium rude sp. n. (30-35), L. latibasale sp. n. (36-44) and L. ascendens sp. n. (45): habitus (30, 36); forebody $(31,37)$; male sternite VII $(32,38)$; male sternite VIII $(33,40)$; aedeagus in lateral and in ventral view (34-35, 41-42); posteromedian portion of male sternite VII (39); female sternite VIII (43); female tergites IX-X (44-45). Scale bars: 30-31, 36-37: 1.0 mm; 32-35, 38, 40-45: $0.5 \mathrm{~mm} ; 39: 0.2 \mathrm{~mm}$. 
Description: Body length $5.2 \mathrm{~mm}$; length of forebody $2.5 \mathrm{~mm}$. Habitus as in Fig. 30. Coloration: forebody darkbrown; abdomen blackish-brown; legs dark-yellowish; antennae reddish.

Head (Fig. 31) as long as broad; punctation sparse and coarse; interstices much broader than diameter of punctures, without microreticulation, glossy. Eyes small, composed of approximately 15 ommatidia, approximately one-fifth as long as postocular region in dorsal view. Antenna $1.4 \mathrm{~mm}$ long.

Pronotum (Fig. 31) 1.24 times as long as broad and as broad as head; punctation slightly less coarse than that of head; midline broadly impunctate; interstices without microsculpture.

Elytra (Fig. 31) 0.65 times as long as pronotum; punctation rather dense, coarse, and shallow; interstices without distinct microsculpture. Hind wings completely reduced.

Abdomen slightly broader than elytra; punctation distinct and moderately dense; interstices with fine microreticulation; posterior margin of tergite VII without palisade fringe; tergite VIII with weakly convex posterior margin.

$\mathrm{o}^{\star}$ : protarsomeres I-IV moderately dilated; sternite VII (Fig. 32) moderately transverse, with unmodified pubescence and very weakly concave posterior margin; sternite VIII (Fig. 33) weakly transverse, 1.05 times as broad as long, with unmodified pubescence, posterior excision very small, posterior margin on either side of posterior excision weakly produced; aedeagus (Figs 34-35) $0.83 \mathrm{~mm}$ long and symmetric; ventral process curved and apically acute in lateral view; dorsal plate with very long, distinctly sclerotized and apically hooked (lateral view) apical portion, and with very short basal portion; internal sac with pair of long spines.

o: unknown.

Comparative notes: As can be inferred from the external (head without microsculpture) and the male sexual characters (posterior margin of sternite VIII produced on either side of posterior excision; aedeagus with long and apically hooked dorsal plate and with long internal spines), L. rude belongs to the L. emodense species group, which previously included four species from central Nepal: L.emodense CoIffait, 1975 (Annapurna), L. annapurnense Assing, 2012 (Annapurna), L. curvum Assing, 2012 (Dhaulagiri), and L. spinosissimum Assing, 2012 (Lamjun Himal). The new species is distinguished from all of them by the practically unmodified male sternite VII, the smaller posterior excision and unmodified pubescence of the male sternite VIII, and by the morphology of the aedeagus (shapes of ventral process, of dorsal plate, and of the internal spines). For illustrations of the other species of the L. emodense group see Assing (2012).
Distribution and natural history: The type locality is situated in the southern Dhaulagiri range (Map 1) at an altitude of 3100-3300 m.

\section{Lathrobium inustum CoIfFAIT, 1982}

Material examined: Nepal: $10^{\star}$, Karnali Province, NE Jumla, $5 \mathrm{~km} \mathrm{~N}$ Maharigaon, $29^{\circ} 21^{\prime} \mathrm{N}, 82^{\circ} 23^{\prime} \mathrm{E}, 3700 \mathrm{~m}$, 6.VII.1999, leg. Weigel (NME); $10^{\star}$, Jumla District, $N$ Maharigaon, $29^{\circ} 21^{\prime} \mathrm{N}, 82^{\circ} 23^{\prime} \mathrm{E}, 3750 \mathrm{~m}, 6 . \mathrm{VII} .1999$, leg. Hartmann (NME).

Comment: The distribution of L. inustum, a species of the L. jumlense group, is confined to few localities near Maharigaon and Talphi in Jumla District, West Nepal (Assing 2012).

\section{Lathrobium fodens Assing, 2012 \\ (Map 2)}

Material examined: Nepal: 22 exs., Karnali Province, Jumla District, $5 \mathrm{~km}$ E Churta, 3400 m, 5.V.1995, leg. Weigel (NME, cAss); 7 exs., Jumla District, SE Churta, 3400 m, sifted, 6.V.1995, leg. Weipert (NME, cAss); 2 exs., Jumla District, $6 \mathrm{~km}$ E Churta, deciduous forest, $3200 \mathrm{~m}$, 18.V.1995, leg. Hartmann (NME, cAss); 17 exs., Jumla District, $10 \mathrm{~km}$ E Churta, $3500 \mathrm{~m}$, sifted, 5.-6.V.1995, leg. Hartmann (NME, cAss); $10^{\star}$, Jumla District, $3 \mathrm{~km} \mathrm{E}$ Churta, $29^{\circ} 11^{\prime} \mathrm{N}, 82^{\circ} 28^{\prime} \mathrm{E}, 3400 \mathrm{~m}, 6 . \mathrm{VI} .1997$, leg. Weigel (cAss); 7 exs., border between Jumla and Dolpa Districts, Bavaria Lagna pass, $29^{\circ} 10^{\prime} \mathrm{N}, 82^{\circ} 29^{\prime} \mathrm{E}, 3200-3800 \mathrm{~m}$, 6.VI.1997, leg. Hartmann (NME, cAss).

Comment: This species is subject to a pronounced sexual size dimorphism, males being noticeably larger than females (length of forebody in $\sigma^{\top} \sigma^{\top} 2.7-3.0 \mathrm{~mm}$, in 우 9 2.4-2.7 mm). The known distribution is confined to the region to the east of Churta in Jumla District, West Nepal (Map 2).

\section{Lathrobium latibasale sp. $\mathrm{n}$. \\ (Figs 38-44, Map 1)}

Type material: Holotype $\sigma^{*}$ : "NEPAL oc. Distr. Jumla, Gothichaur Khola, SE, 10.VI.1997, 3400-3600 m, Rhododend. Buschzone, leg. A. Weigel GSB / Holotypus $\sigma^{\star}$ Lathrobium latibasale sp. n., det. V. Assing 2013" (NME). Paratypes: $2 \sigma^{\star} \sigma^{\star}, 3$ 우: same data as holotype (NME, cAss).

Etymology: The specific epithet is an adjective composed of the Latin adjectives latus (broad) and basalis (basal) and alludes to the broad base of the ventral process (ventral view), the character best distinguishing this species from the similar L. fodens. 


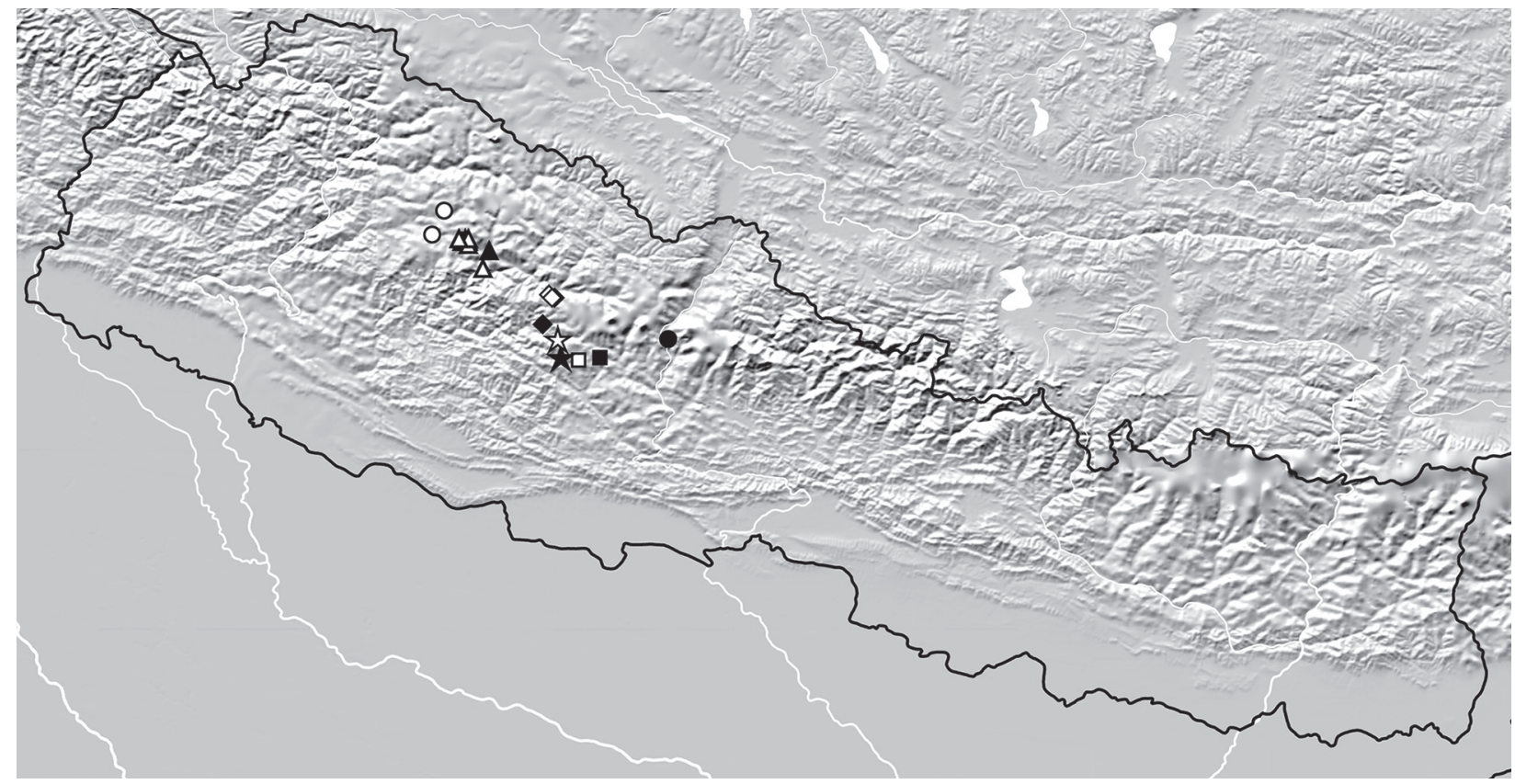

Map 2: Distributions of Lathrobium species in Nepal: L. flexaculeatum (white square), L. rectaculeatum (black star), L. curvaculeatum (white star), L. hebes (black square), L. imberbe (black triangle), L. plicatum (black diamond), L. calcaratum (circles; white circles: new records; black circle: type locality), L. fodens (white triangles), L. aculeatum (white diamonds).

Description: Body size sexually dimorphic: body length in $\sigma^{\top} \sigma^{\top}$ 6.4-6.8 mm, in 우 $9.3-6.2 \mathrm{~mm}$; length of forebody in $\sigma^{\top} o^{\top} 2.8-3.0 \mathrm{~mm}$, in 우 ㅇ $2.5-2.7 \mathrm{~mm}$. Habitus as in Fig. 36. External characters (Figs 36-37) as in L. fodens.

$0^{*}$ : protarsomeres I-IV moderately dilated; posterior margin of tergite VIII convex; sternite VII (Fig. 38) distinctly transverse, posterior margin with relatively shallow bisinuate median excision, margin of this excision with comb of approximately 30 long pectinate setae, anterior to this comb with cluster of numerous stout black setae (Fig. 39); sternite VIII (Fig. 40) weakly transverse and with shallow impression in posteromedian portion, middle of this impression and anterior portion of sternite without pubescence, remainder of sternite with sparse pubescence, posterior excision of almost semi-circular shape; aedeagus (Figs 41-42) approximately $1.25 \mathrm{~mm}$ long, symmetric; ventral process with broad base (ventral view) and apically shaped like a long straight sting; dorsal plate broad and short, in lateral view curved; internal sac without sclerotized structures.

ㅇ: protarsomeres I-IV moderately dilated, slightly less so than in male; posterior margin of tergite VIII weakly convex; sternite VIII (Fig. 43) approximately 1.1 times as long as broad, sparsely pubescent, and with strongly convex posterior margin; tergite IX (Fig. 44) undivided in the middle and with moderately long, apically acute postero-lateral processes; tergite X (Fig. 44) flat, of oval shape, and indistinctly longer than antero-median portion of tergite IX.
Comparative notes: As can be inferred from the highly similar external and sexual characters, L. latibasale is the adelphotaxon of L. fodens of the L. pectinatum group, which too is distributed in Jumla District. The new species is reliably distinguished from L. fodens only by the morphology of the aedeagus (base of ventral process broader in ventral view).

Distribution and natural history: The type locality is situated in Jumla District, Karnali Province, West Nepal (Map 1). The specimens were collected in the rhododendron shrub zone at an altitude of 3400-3600 m.

Lathrobium calcaratum Assing, 2012 (Map 2)

Material examined: Nepal: $1 \sigma^{\star}$, Karnali Province, Jumla District, $2 \mathrm{~km} \mathrm{~W}$ Gothichaur, $29^{\circ} 12^{\prime} \mathrm{N}, 82^{\circ} 19^{\prime} \mathrm{E}, 2850 \mathrm{~m}$, forest, 8.VI.1997, leg. Hartmann (NME); $1 \sigma^{\star}$, Jumla District, NE Talphi, Maharigaun, 3300 m, 20.VI.1997, leg. Weigel (cAss).

Comment: The original description of $L$. calcaratum is based on a unique male from the Kali-Gandaki valley (Assing 2012). The distance between the above records from West Nepal and the type locality (Map 2) suggests that the holotype is mislabelled. Himalayan Lathrobium species generally have highly restricted distributions. The collector of the holotype, the late Herbert Franz, conducted a field trip to Jumla District and to the KaliGandaki valley in the same year. 


\section{Lathrobium eques sp. n.}

(Figs 46-55, Map 1)

Type material: Holotype $\sigma^{\star}:$ "NEPAL oc. Distr. Jumla,

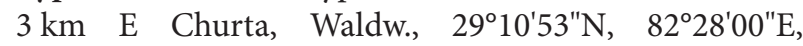
06.VI.1997 3400 m, leg. A. Weigel GSB / Holotypus $0^{\star}$ Lathrobium eques sp. n., det. V. Assing 2013" (NME). Paratypes: $10^{\star}, 1$ ㅇ: same data as holotype (NME, cAss).

Etymology: The specific epithet (Latin, noun: horseman, equestrian) alludes to the spur-like modifications of the male metafemora.

Description: Body length 5.3-5.8 mm; length of forebody $2.6-2.9 \mathrm{~mm}$. Habitus as in Fig. 46. Coloration: whole body, including appendages, reddish.

Head (Fig. 47) 1.02-1.07 times as long as broad; punctation sparse and moderately coarse; interstices much broader than diameter of punctures, with distinct microreticulation. Eyes small, composed of approximately 10 ommatidia, one-sixth to one-fifth as long as postocular region in dorsal view. Antenna 1.4-1.5 mm long.

Pronotum (Fig. 47) 1.20-1.25 times as long as broad and about as broad as head; posterior margin concave; punctation similar to that of head; midline broadly impunctate; interstices without microsculpture.

Elytra (Fig. 47) rather broad and approximately 0.6 times as long as pronotum; punctation fine and sparse; interstices without distinct microsculpture. Hind wings completely reduced. Protarsomeres I-IV and metafemora with distinct sexual dimorphism.

Abdomen approximately as broad as elytra; punctation distinct and moderately dense; interstices with shallow microsculpture; posterior margin of tergite VII without palisade fringe; posterior margin of tergite VIII convex. $\sigma^{\star}$ : protarsomeres I-IV strongly dilated; metafemur with a pronounced spur-like posterior extension at apical third (Fig. 48); sternite VII (Fig. 49) moderately transverse, with median impression, on either side of this impression with a cluster of stout black setae posteriorly, posterior excision of transversely trapezoid shape, margin of the excision with a comb of 25-30 stout palisade setae; sternite VIII (Fig. 50) approximately as long as broad, in median portion extensively without pubescence, posterior excision moderately deep, lateral margins of this excision with a row of dense short setae; aedeagus (Figs 51-52) approximately $0.95 \mathrm{~mm}$ long, dorso-ventrally somewhat flattened; ventral process basally broad, apically asymmetric and nearly stingshaped; dorsal plate short, basally broad, and apically with a sting-like extension (Fig. 53); internal sac with membranous structures.

i: protarsomeres I-IV moderately dilated; metafemur with weakly pronounced posterior convexity at apical third; sternite VIII (Fig. 54) nearly 1.2 times as long as broad, with convex posterior margin; tergite IX (Fig. 55) undivided in the middle, postero-lateral processes short, only slightly extending beyond apex of tergite X; tergite $\mathrm{X}$
(Fig. 55) flat, of oval shape, and approximately 1.6 times as long as antero-median portion of tergite IX.

Comparative notes: The similarly modified male sexual characters (modifications of metafemora; shapes and chaetotaxy of sternites VII-VIII; similarly shaped, asymmetric ventral process of the aedeagus) suggest that L. eques represents the adelphotaxon of L. calcaratum, from which it is distinguished only by the less broad posterior excision of the male sternite VII, the slightly less deep posterior excision of the male sternite VIII, and by the morphology of the aedeagus (apical portion of ventral process much more slender; ventral process of different shape also in lateral view). For illustrations of L. calcaratum see Assing (2012).

Distribution and natural history: The type locality is situated in Jumla District, Karnali Province, West Nepal (Map 1), at an altitude of $3400 \mathrm{~m}$. The material was collected together with a male of $L$. fodens.

\section{Lathrobium equitans sp. $\mathrm{n}$. \\ (Figs 56-61, Map 1)}

Type material: Holotype o : "NEPAL, N. Dhorpatan, Porkapan, 1977, P. Morvan / Holotypus o Lathrobium equitans sp. n., det. V. Assing 2013" (cRou).

Paratypes: $2 o^{\top} o^{\star}$ : same data as holotype (cRou, cAss).

Etymology: The specific epithet is the present participle of the Latin verb equitare (to ride) and alludes to the spur-like modifications of the male metafemora.

Description: Body length 4.8-5.2 mm; length of forebody $2.4-2.5 \mathrm{~mm}$. Habitus similar to that of L. eques. Coloration: whole body, including appendages, reddish. Head approximately as long as broad; punctation sparse and rather fine to moderately coarse; interstices much broader than diameter of punctures, with distinct microreticulation. Eyes small, composed of approximately 10 ommatidia, approximately one-sixth as long as postocular region in dorsal view. Antenna $1.4 \mathrm{~mm}$ long.

Pronotum 1.20-1.25 times as long as broad and about as broad as head; posterior margin distinctly concave; punctation denser and slightly coarser than that of head; midline broadly impunctate; interstices without microsculpture.

Elytra approximately 0.6 times as long as pronotum; punctation fine and sparse; interstices without distinct microsculpture. Hind wings completely reduced. Male metafemora and metatibiae conspicuously modified.

Abdomen approximately as broad as elytra; punctation distinct and moderately dense; interstices with shallow microsculpture; posterior margin of tergite VII without palisade fringe; posterior margin of tergite VIII convex.

$\sigma^{\star}$ : protarsomeres I-IV strongly dilated; metafemur compressed, strongly dilated posteriorly, and with a pronounced spur-like posterior extension (Fig. 56); 


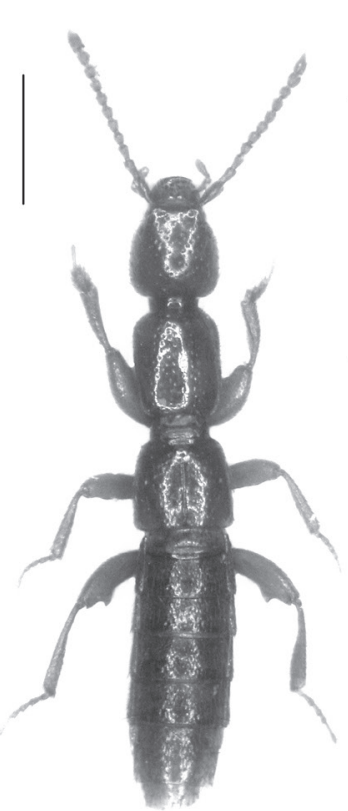

46

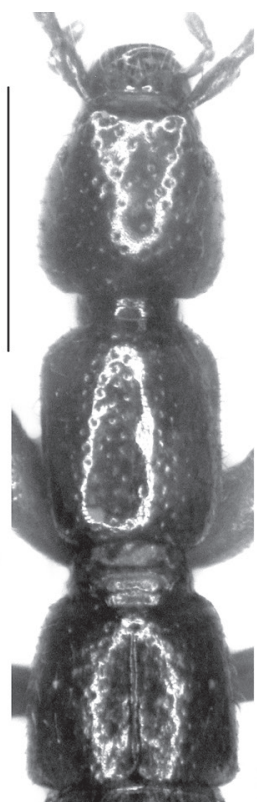

47

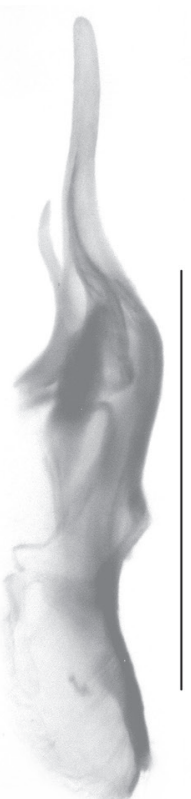

51

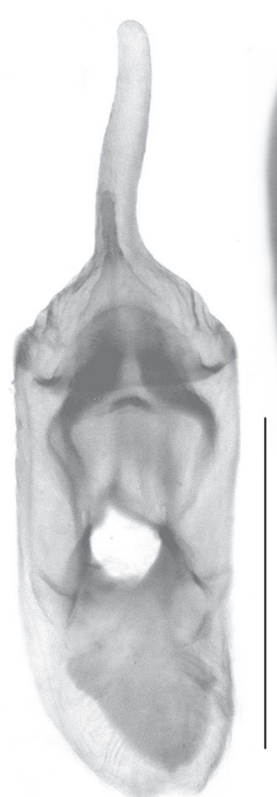

52

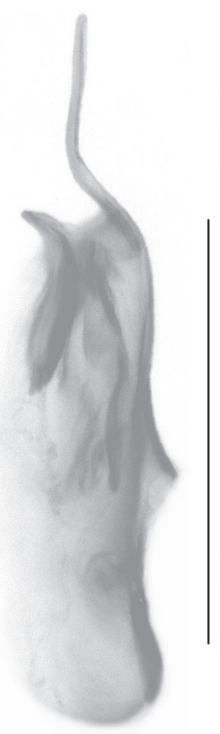

59

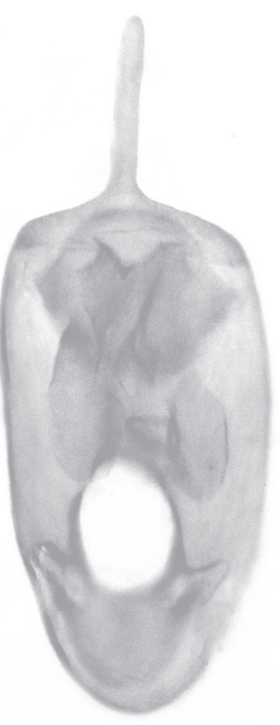

60
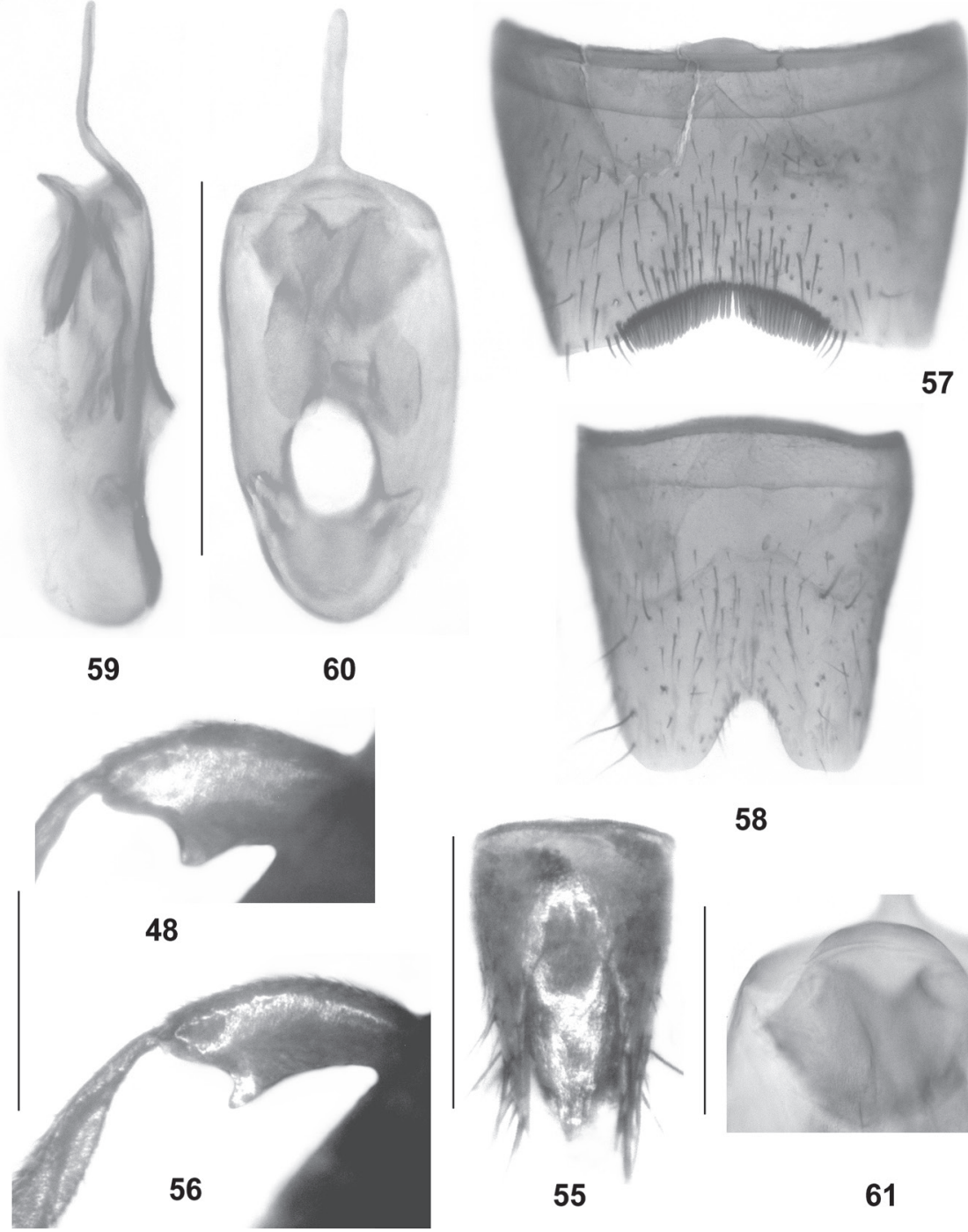

57
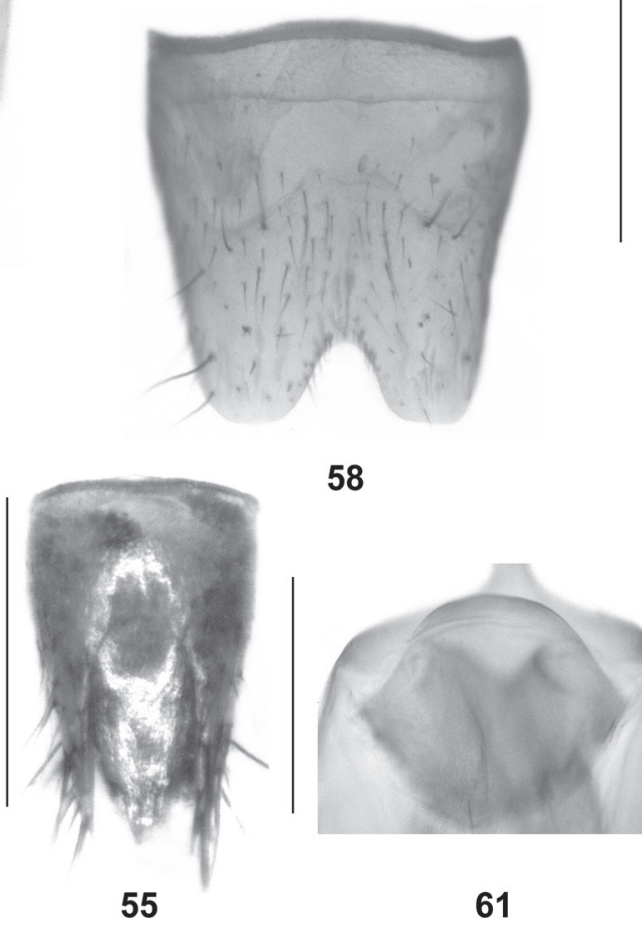

58
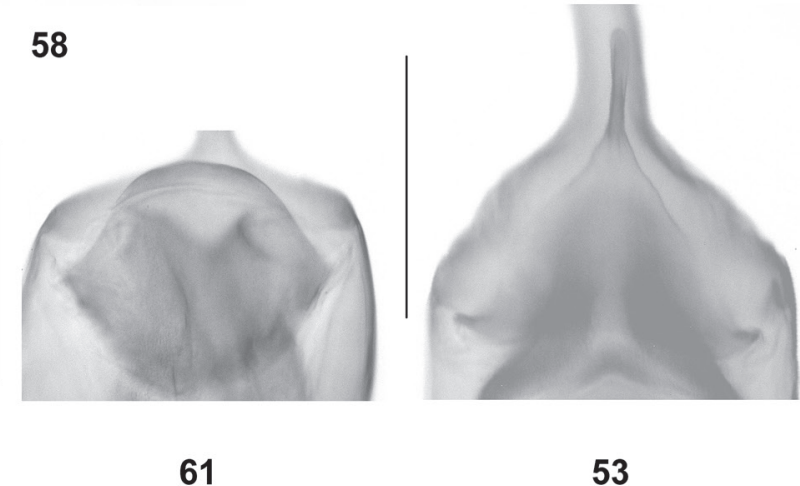

53

Figs 46-61: Lathrobium eques sp. n. (46-55) and L. equitans sp. n. (56-61): male habitus (46); forebody (47); male metafemur $(48,56)$; male sternite VII $(49,57)$; male sternite VIII $(50,58)$; aedeagus in lateral and in ventral view $(51-52,59-60)$; dorsal plate of aedeagus in dorsal view $(53,61)$; female sternite VIII (54); female tergites IX-X (55). Scale bars: 46-47: 1.0 mm; 48-52, 54-60: $0.5 \mathrm{~mm} ; 53,61: 0.2 \mathrm{~mm}$. 
metatibia strongly dilated in apical two-thirds, compressed, and excavate on inner side (Fig. 56); sternite VII (Fig. 57) distinctly transverse and with median impression, this impression with moderately dense black setae, posterior margin concavely excised in the middle, this excision with comb of approximately 40 palisade setae; sternite VIII (Fig. 58) approximately as long as broad and sparsely pubescent, posterior excision moderately deep, lateral margins of this excision with a row of dense short setae; aedeagus (Figs 59-60) approximately $0.85 \mathrm{~mm}$ long, dorso-ventrally somewhat flattened, and nearly symmetric; ventral process broad and apically sting-shaped; dorsal plate short, broad, and apically convex in dorsal view (Fig. 61); internal sac with membranous structures.

o: unknown.

Comparative notes: Among the species of the L. pectinatum group, L. equitans is readily identified based on the conspicuous modifications of the male metafemora and metatibiae, on the shapes and chaetotaxy of the male sternites VII and VIII, as well as on the morphology of the aedeagus. The similarly modified male metafemora suggest that it is closely allied to L. calcaratum and L. eques. For illustrations of other species of the L. pectinatum group see Assing (2012).

Distribution and natural history: The type locality is situated in the Dhaulagiri range in central Nepal (Map 1). Additional data are not available.

\section{Lathrobium abruptum sp. n.}

(Figs 62-69, Map 1)

Type material: Holotype ơ: "NEPAL Prov. Bheri, Distr. Surkhet, $20 \mathrm{~km} \mathrm{~N}$ Surkhet $2000 \mathrm{~m} \mathrm{01.VI.1995} \mathrm{leg.}$ A. Weigel / Holotypus o Lathrobium abruptum sp. n., det. V. Assing 2013" (NME).

Paratypes: 2 우 우 : same data as holotype (NME, cAss).

Etymology: The specific epithet (Latin, adjective) refers to the abruptly narrowed ventral process (ventral view).

Description: Body length 4.7-5.5 mm; length of forebody $2.4 \mathrm{~mm}$. Habitus as in Fig. 62. Coloration: forebody reddish to dark-reddish; abdomen reddish to darkbrown; legs and antennae reddish.

Head (Fig. 63) approximately 1.1 times as long as broad; punctation sparse and moderately coarse; interstices on average distinctly broader than diameter of punctures, with shallow microreticulation. Eyes small, composed of approximately 10 ommatidia, approximately one-fifth as long as postocular region in dorsal view. Antenna approximately $1.3 \mathrm{~mm}$ long.

Pronotum (Fig. 63) slender, 1.22-1.30 times as long as broad and about as broad as head or slightly broader; punctation similar to that of head; midline broadly impunctate; interstices without microsculpture.
Elytra (Fig. 63) rather broad and approximately 0.6 times as long as pronotum; punctation fine and sparse; interstices without distinct microsculpture. Hind wings completely reduced. Protarsomeres I-IV with weakly pronounced sexual dimorphism.

Abdomen only slightly broader than elytra; punctation rather coarse and not very dense; interstices with shallow microsculpture; posterior margin of tergite VII without palisade fringe.

$\mathrm{o}^{\star}$ : protarsomeres I-IV moderately dilated; posterior margin of tergite VIII convex; sternite VII (Fig. 64) distinctly transverse, posterior margin rather shallowly concave in the middle, margin of this concavity with comb of approximately 25 long pectinate setae, anterior to this comb with rather sparse long black setae; sternite VIII (Fig. 65) weakly transverse, in the middle with extremely short, fine, and sparse pubescence, posterior excision rather deep and somewhat asymmetric; aedeagus (Figs 66-67) $1.1 \mathrm{~mm}$ long and nearly symmetric; ventral process basally broad and apically extending into a long and extremely fine, acute spine; dorsal plate broad and short, in lateral view curved; internal sac with dark membranous structures.

+ : protarsomeres I-IV moderately dilated, slightly less so than in male; tergite VIII of similar shape as in male; sternite VIII (Fig. 68) approximately 1.1 times as long as broad, sparsely pubescent, posterior margin obtusely angled in the middle; tergite IX (Fig. 69) undivided in the middle, postero-lateral processes short, only slightly extending beyond apex of tergite X; tergite X (Fig. 69) flat, of oval shape, and approximately as long as anteromedian portion of tergite IX.

Comparative notes: Based on the male sexual characters (chaetotaxy of the male sternite VII; shape of the male sternite VIII; sting-shaped ventral process of the aedeagus), L. abruptum undoubtedly belongs to the L. pectinatum group. It differs from other representatives of this group particularly by the shape and chaetotaxy of the male sternite VII and by the structure of the aedeagus.

Distribution and natural history: The type locality is situated in Surkhet District, Bheri Province, West Nepal (Map 1), at an altitude of $2000 \mathrm{~m}$.

\section{Lathrobium kemum sp. n. \\ (Figs 70-78, 96, Map 1)}

Type material: Holotype $0^{\star}$ : "NEPAL W Dhaulagiri, Kem Danda 31-3200 m, 28 $28^{\prime} 37^{\prime \prime N}$, 82 $58^{\prime} 34^{\prime \prime E}$, 18.IX.2012 leg. J. Schmidt / Holotypus ơ Lathrobium kemum sp. n., det. V. Assing 2013” (NME).

Paratypes: $18 \sigma^{\star} o^{\star}, 10$ 우 우 [partly teneral]: same data as holotype (NME, cAss).

Etymology: The specific epithet is an adjective derived from the type locality (Kem Danda). 


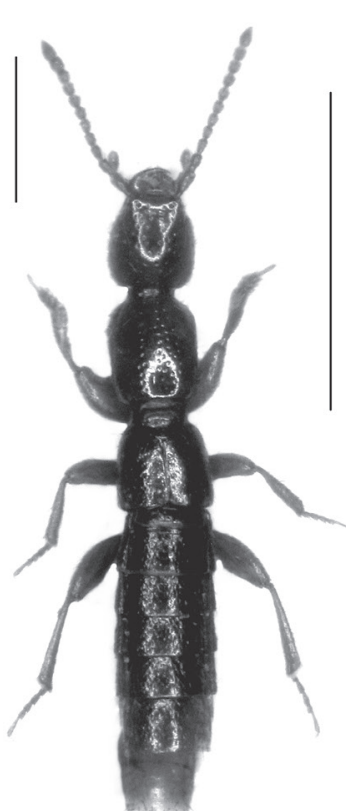

62

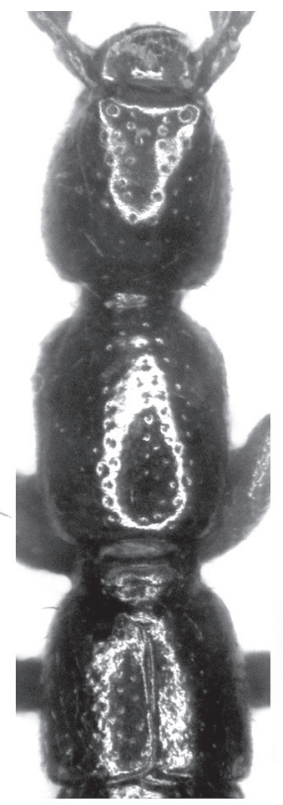

63

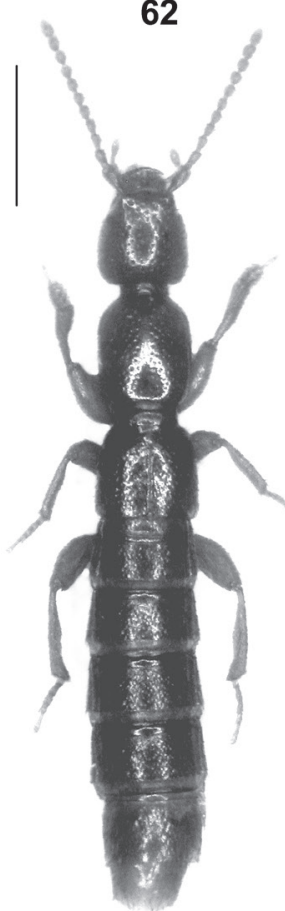

70

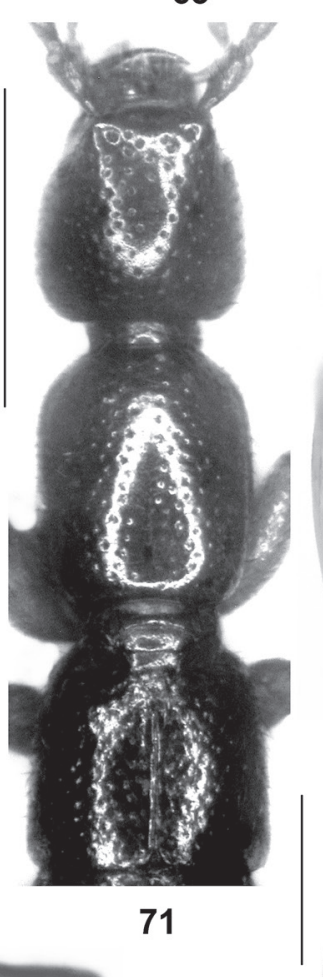

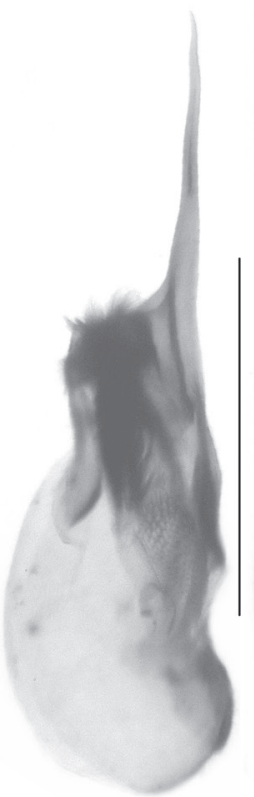

66

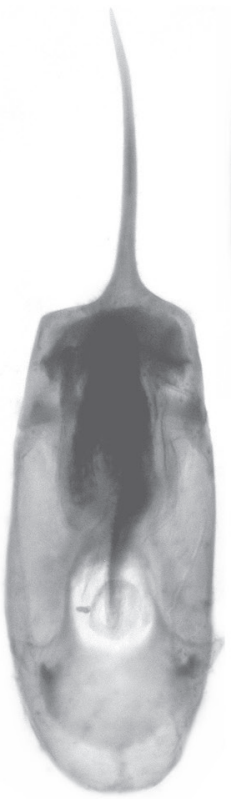

67

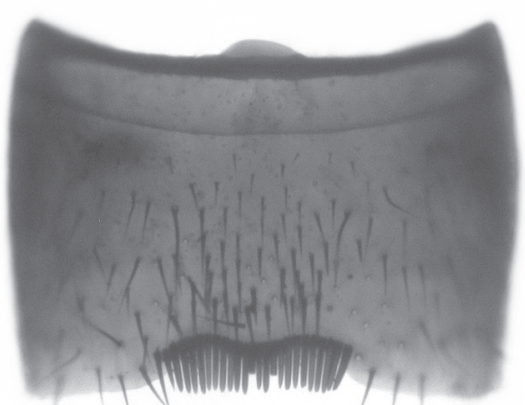

64

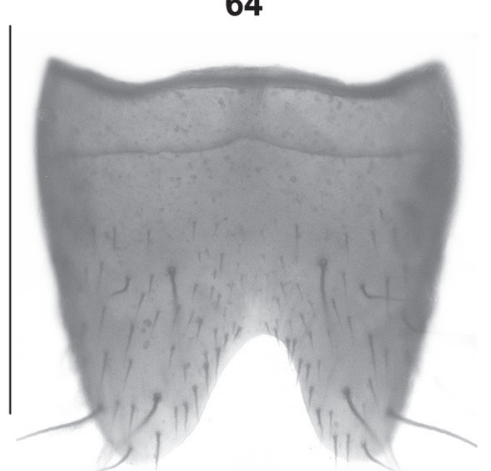

65

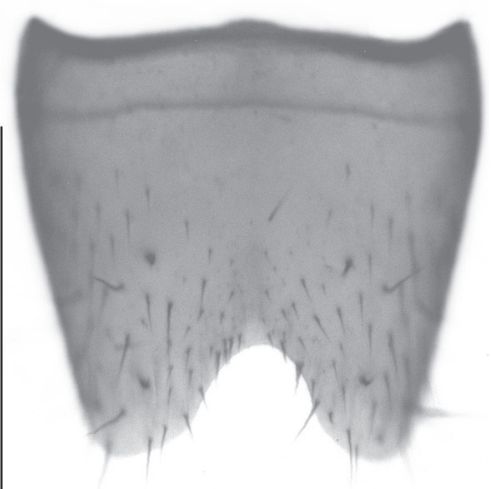

74
75

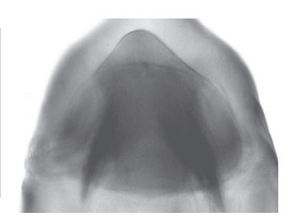

77

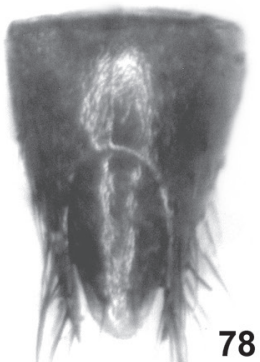

76

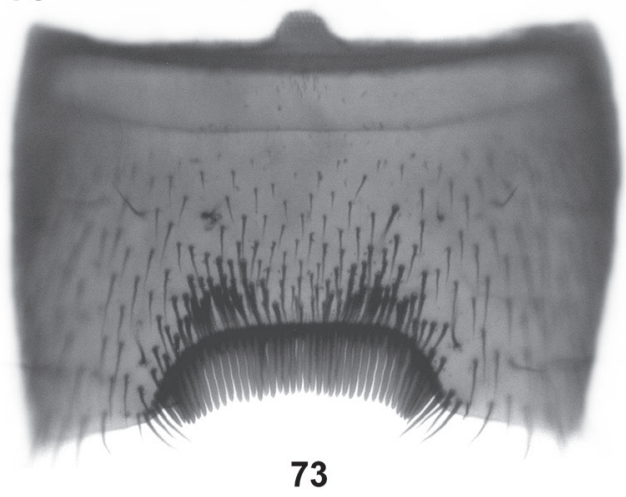

73

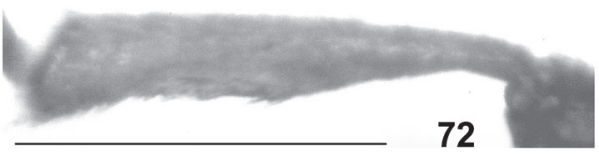

Figs 62-78: Lathrobium abruptum sp. n. (62-69) and L. kemum sp. n. (70-78): male habitus (62, 70); forebody (63, 71); male sternite VII $(64,73)$; male sternite VIII $(65,74)$; aedeagus in lateral and in ventral view $(66-67,75-76)$; female sternite VIII (68); female tergites IX-X $(69,78)$; metatibia (72); dorsal plate of aedeagus in dorsal view (77). Scale bars: 62-63, 70-71: 1.0 mm; 64-69, 72-76, 78: $0.5 \mathrm{~mm} ; 77: 0.2 \mathrm{~mm}$. 
Description: Body length 5.0-6.0 mm; length of forebody $2.3-2.5 \mathrm{~mm}$; males on average larger than females. Habitus as in Fig. 70. Coloration: whole body reddish. Head (Fig. 71) approximately as long as broad; punctation moderately dense and moderately coarse, sparser in median dorsal portion; interstices with distinct microreticulation. Eyes small, composed of approximately 10 ommatidia, approximately one-sixth as long as postocular region in dorsal view. Antenna 1.2-1.4 mm long. Pronotum (Fig. 71) approximately 1.2 times as long as broad and about as broad as head; punctation similar to that of head; midline moderately broadly impunctate; interstices without microsculpture.

Elytra (Fig. 71) approximately 0.6 times as long as pronotum; punctation fine and sparse; interstices without distinct microsculpture. Hind wings completely reduced. Protarsomeres I-IV without appreciable sexual dimorphism, distinctly dilated in both sexes; metatibia (Fig. 72) dilated and strongly flattened in apical two-thirds in both sexes.

Abdomen slightly broader than elytra; punctation distinct and moderately dense; interstices with shallow microsculpture; posterior margin of tergite VII without palisade fringe; tergite VIII with convex posterior margin.

$o^{\star}$ : sternite VII (Fig. 73) strongly transverse, in posterior portion with a cluster of long and stout black setae on either side of middle, posterior margin with broad and not very deep posterior excision, margin of this excision with a comb of 30-40 very long palisade setae; sternite VIII (Fig. 74) weakly transverse, in antero-median portion extensively without pubescence, posterior excision rather deep, broad, and anteriorly rounded; aedeagus (Figs 75-76) approximately $0.95 \mathrm{~mm}$ long and somewhat asymmetric; ventral process short, basally broad, and apically of triangular shape in ventral view; dorsal plate broad and short (Fig. 77); internal sac without appreciable structures.

o : sternite VIII (Fig. 96) approximately 1.1 times as long as broad and with convex posterior margin; tergite IX (Fig. 78) undivided in the middle, postero-lateral processes short, only slightly extending beyond apex of tergite X; tergite X (Fig. 78) flat, of oval shape, and approximately 1.4 times as long as antero-median portion of tergite IX.

Comparative notes: Among the species of the L. pectinatum group, L. kemum is characterized by the compressed metatibiae (in male and females), the shapes and chaetotaxy of the male sternites VII and VIII, and particularly by the morphology of the aedeagus. The similarly modified metatibiae, the similarly modified morphology of the aedeagus, and the similar male secondary sexual characters suggest that L. kemum is closely related to L. pectinatum CoIfFAIT, 1981 (Manaslu), L. compressicrus Assing, 2012 (Manaslu), L. barbatum Assing, 2012 (Annapurna), L. barbulatum Assing, 2012 (Annapurna), and L. cavicrus Assing, 2012 (Manaslu).
Distribution and natural history: The type locality is situated in the Dhaulagiri range, Central Nepal (Map 1), at an altitude of $3100-3200 \mathrm{~m}$. Some of the specimens are more or less distinctly teneral.

\section{Lathrobium flexaculeatum sp. $\mathrm{n}$. (Figs 79-88, Map 2)}

Type material: Holotype o : "NEPAL SW Dhaulagiri, E Dhorpatan 3000 m, 22.IX.12 lg. J. Schmidt, 28³0'08"N, $83^{\circ} 07^{\prime} 45^{\prime \prime} \mathrm{E} / \mathrm{Holotypus} 0^{\star}$ Lathrobium flexaculeatum sp. n., det. V. Assing 2013" (NME).

Paratypes: 1 , 1 sex? [posterior portion of abdomen missing]: same data as holotype (NME, cAss).

Etymology: The specific epithet is an adjective composed of the Latin adjectives flexus (bent) and aculeatus (with a sting). It alludes to the curved sting-shaped apex of the ventral process of the aedeagus.

Description: Body length 5.4-5.6 mm; length of forebody $2.6-2.8 \mathrm{~mm}$. Habitus as in Fig. 79. Coloration: forebody reddish to dark-brown; abdomen dark-brown to blackish-brown; legs and antennae reddish.

Head (Fig. 80) weakly oblong, approximately 1.04 times as long as broad; punctation moderately dense and moderately coarse, sparser in median dorsal portion; interstices with distinct microreticulation. Eyes small, composed of approximately 10 ommatidia, one-sixth to one-fifth as long as postocular region in dorsal view. Antenna 1.3-1.4 mm long.

Pronotum (Fig. 80) approximately 1.25 times as long as broad and about as broad as head; punctation similar to that of head; midline broadly impunctate; interstices without microsculpture.

Elytra (Fig. 80) approximately 0.6 times as long as pronotum; punctation fine and sparse; interstices without distinct microsculpture. Hind wings completely reduced. Protarsomeres I-IV with weakly pronounced sexual dimorphism; metatibia compressed in apical two-thirds in both sexes; metafemora sexually dimorphic.

Abdomen slightly broader than elytra; punctation distinct and moderately dense; interstices with shallow microsculpture; posterior margin of tergite VII without palisade fringe.

$0^{*}$ : protarsomeres I-IV strongly dilated; metafemur posteriorly with a long and oblique (more pronounced basally than apically) carina in the middle (Fig. 81); sternite VII (Fig. 82) strongly transverse, in posterior portion with extensive cluster of numerous long and stout black setae, posterior margin with broad and not very deep posterior excision, margin of this excision with a comb of approximately 35 long palisade setae; sternite VIII (Fig. 83) approximately 1.15 times as broad as long, in antero-median portion extensively without pubescence, posterior excision moderately deep, moderately broad, and anteriorly rounded, lateral margins of this excision with a row of dense short setae; aedeagus (Figs 84-85) 


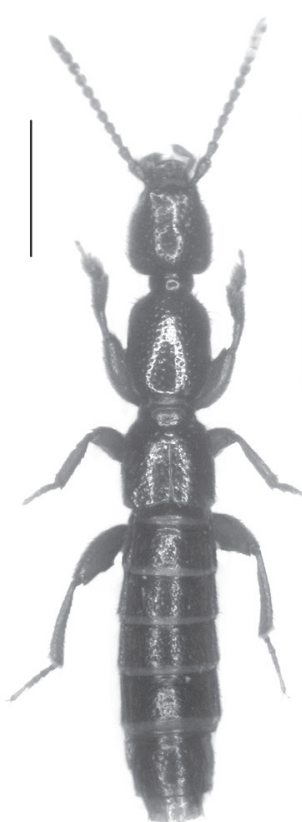

79

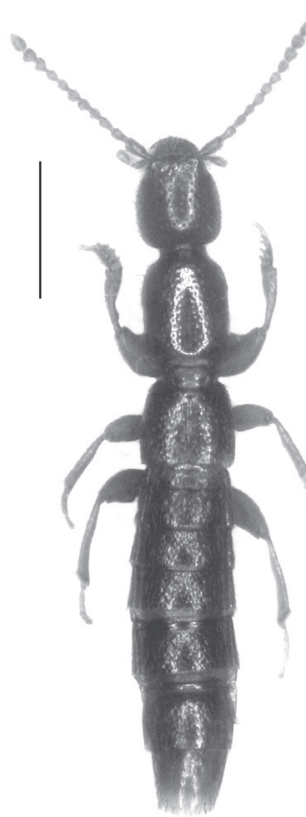

89
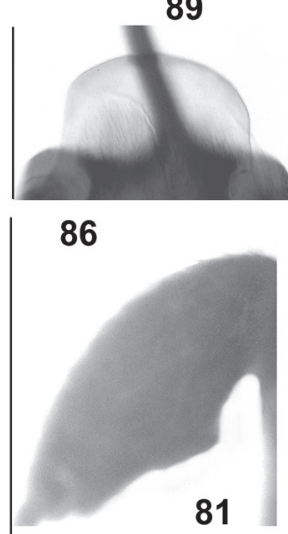

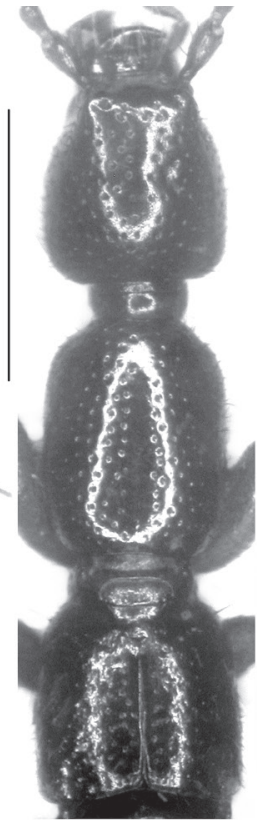

80

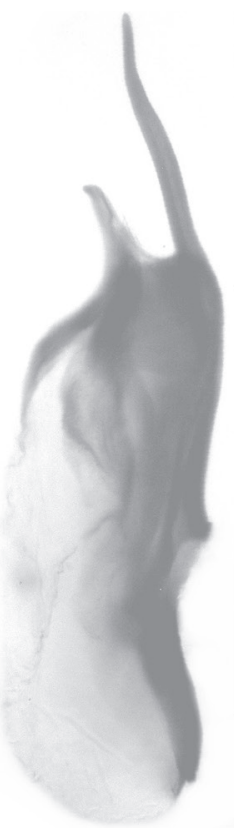

84

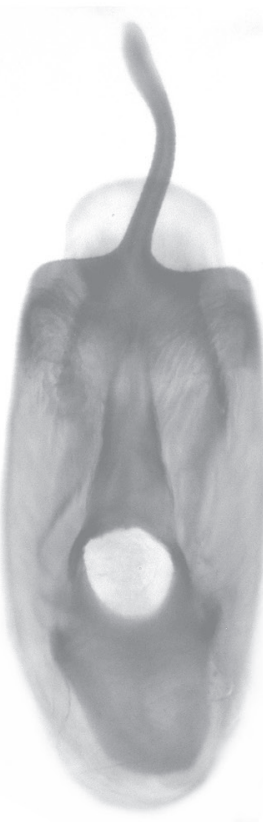

85

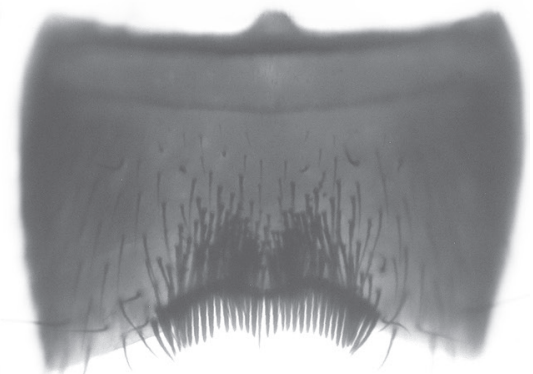

82

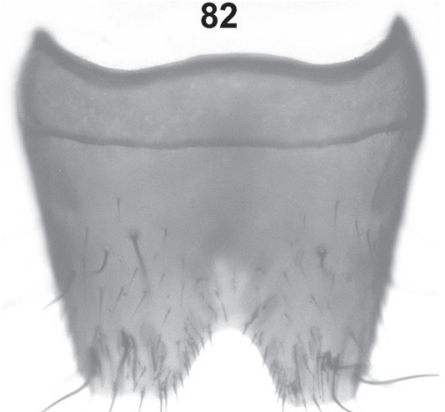

83

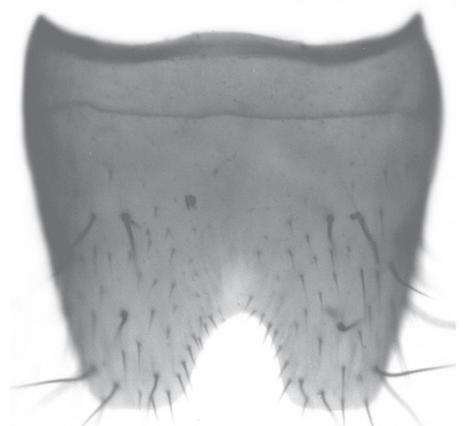

93

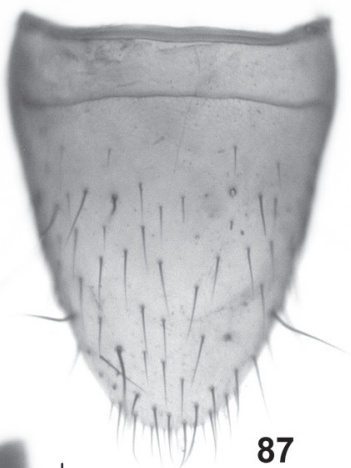

87

94

95
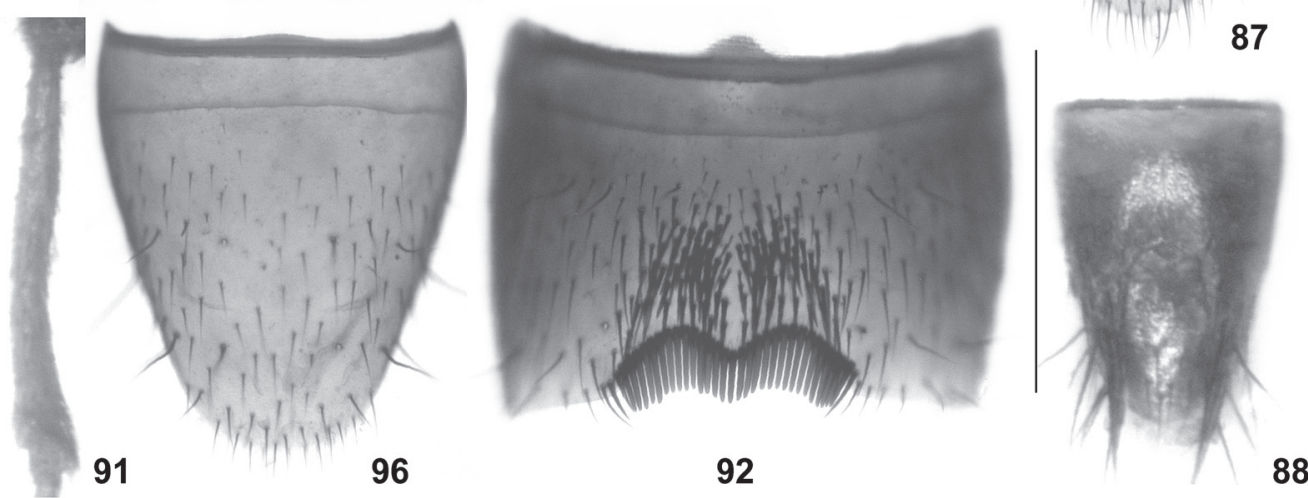

Figs 79-96: Lathrobium flexaculeatum sp. n. (79-88), L. rectaculeatum sp. n. (89-95), and L. kemum sp. n. (96): male habitus (79, 89); forebody $(80,90)$; male metafemur $(81)$; male sternite VII $(82,92)$; male sternite VIII $(83,93)$; aedeagus in lateral and in ventral view (84-85, 94-95); dorsal plate of aedeagus in dorsal view (86); female sternite VIII $(\mathbf{8 7}, \mathbf{9 6})$; female tergites IX-X (88); metatibia (91). Scale bars: 79-80, 89-90: $1.0 \mathrm{~mm}$; 81-85, 87-88, 91-96: $0.5 \mathrm{~mm}$; 86: $0.2 \mathrm{~mm}$. 
approximately $0.95 \mathrm{~mm}$ long and somewhat asymmetric; ventral process basally broad and apically extending into a sinuate spine-shaped process in ventral view; dorsal plate broad, short, and apically weakly convex (Fig. 86); internal sac without appreciable structures.

: protarsomeres I-IV moderately dilated; sternite VIII (Fig. 87) 1.13 times as long as broad and with strongly convex posterior margin; tergite IX (Fig. 88) undivided in the middle, postero-lateral processes short, only slightly extending beyond apex of tergite X; tergite X (Fig. 88) flat, of oval shape, and approximately 1.2 times as long as antero-median portion of tergite IX.

Comparative notes: Among the species of the L. pectinatum group, L.flexaculeatum is characterized by the compressed metatibiae (in male and females), the modifications of the male metafemora, the shapes and chaetotaxy of the male sternites VII and VIII, and by the morphology of the aedeagus.

Distribution and natural history: The type locality is situated in the southwestern Dhaulagiri range, Central Nepal (Map 2), at an altitude of $3000 \mathrm{~m}$.

\section{Lathrobium rectaculeatum $\mathrm{sp} . \mathrm{n}$. (Figs 89-95, Map 2)}

Type material: Holotype $0^{\star}:$ "NEPAL SW Dhaulagiri, NW Dhorpatan 31-3200 m, 28³0'47"N, 8301'59"E / Holotypus $\sigma^{*}$ Lathrobium rectaculeatum sp. n., det. V. Assing 2013" (NME).

Paratypes: $4 \sigma^{\star} \sigma^{*}$ : same data as holotype (NME, cAss).

Etymology: The specific epithet is an adjective composed of the Latin adjectives rectus (straight) and aculeatus (with a sting). It alludes to the straight stingshaped apex of the ventral process of the aedeagus (ventral view) and the presumably close relationship to L. flexaculeatum.

Description: Body length 5.4-6.2 mm; length of forebody $2.5-2.6 \mathrm{~mm}$. Habitus as in Fig. 89. Coloration: forebody reddish; abdomen dark-brown; legs and antennae reddish. Other external characters (Figs 90-91) as in L. flexaculeatum.

$\mathrm{o}^{\star}$ : protarsomeres I-IV strongly dilated; metafemur posteriorly with a weakly pronounced long and oblique (more pronounced basally than apically) carina in the middle; sternite VII (Fig. 92) distinctly transverse, in posteromedian portion with an extensive cluster of numerous long and stout black setae, posterior margin with broad, bisinuate, and shallow posterior excision, margin of this excision with a comb of approximately 30 long palisade setae; sternite VIII (Fig. 93) approximately 1.13 times as broad as long, in the antero-median portion extensively without pubescence, posterior excision moderately deep, moderately broad, and anteriorly rounded, lateral margins of this excision with a row of dense short setae; aedeagus (Figs 94-95) 1.05-1.15 mm long and symmetric; ventral process basally broad and apically extending into a straight spine-shaped process in ventral view; dorsal plate broad and very short; internal sac without appreciable structures.

o: unknown.

Comparative notes: The similar modifications of the male metafemora, the similarly modified male sternites VII and VIII, and the similar morphology of the aedeagus suggest that $L$. rectaculeatum is most closely related to the geographically close $L$. flexaculeatum, from which it differs by the less pronounced modifications of the male metafemora, the less transverse male sternite VII with a distinctly bisinuate posterior excision, and by the larger aedeagus with an apically straight ventral process and with a differently shaped dorsal plate.

Distribution and natural history: The type locality is situated in the southwestern Dhaulagiri range, Central Nepal (Map 2), at an altitude of 3100-3200 m.

\section{Lathrobium curvaculeatum sp. $\mathrm{n}$. (Figs 97-105, Map 2)}

Type material: Holotype $0^{\top}$ : "NEPAL W Dhaulagiri, Thankurb $3250 \mathrm{~m}$, 19.IX.2012, 28³6'32"N, 8301'26"E, leg. J. Schmidt / Holotypus ơ Lathrobium curvaculeatum sp. n., det. V. Assing 2013" (NME).

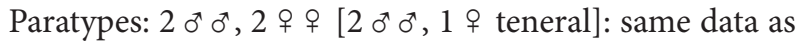
holotype (NME, cAss).

Etymology: The specific epithet is an adjective composed of the past participle of the Latin verb curvare (to curve) and the Latin adjective aculeatus (with a sting). It alludes to the curved sting-shaped apex of the ventral process of the aedeagus.

Description: Body length 4.8-6.4 mm; length of forebody 2.5-2.8 mm; females slightly smaller than males. Habitus as in Fig. 97. Coloration: forebody dark-brown; abdomen blackish-brown; legs dark reddish-brown; antennae darkreddish.

Head (Fig. 98) weakly oblong, approximately 1.04 times as long as broad; punctation moderately dense and moderately coarse, sparser in median dorsal portion; interstices with distinct microreticulation. Eyes small, composed of approximately 10 ommatidia, one-sixth to one-fifth as long as postocular region in dorsal view. Antenna 1.3-1.5 mm long.

Pronotum (Fig. 98) approximately 1.25 times as long as broad and about as broad as head; punctation similar to that of head; midline broadly impunctate; interstices without microsculpture.

Elytra (Fig. 98) approximately 0.6 times as long as pronotum; punctation fine and sparse; interstices without distinct microsculpture. Hind wings completely reduced. Protarsomeres I-IV with pronounced sexual 

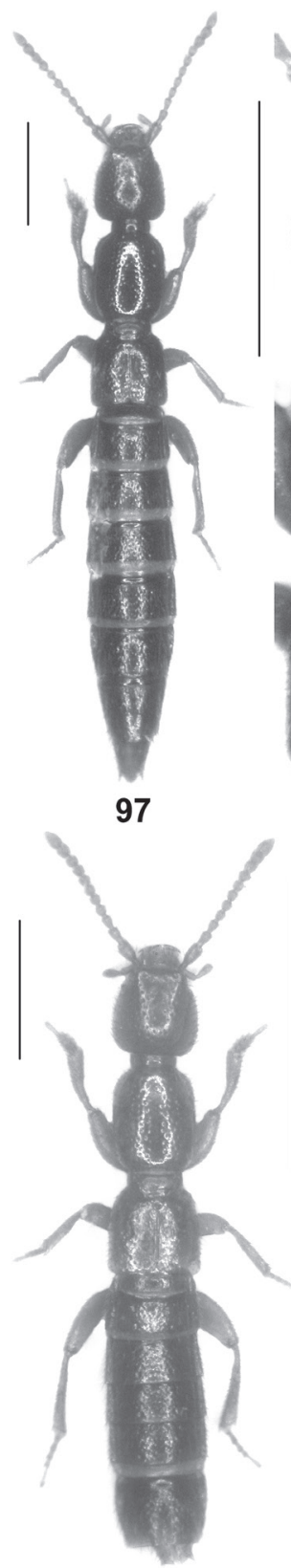

106

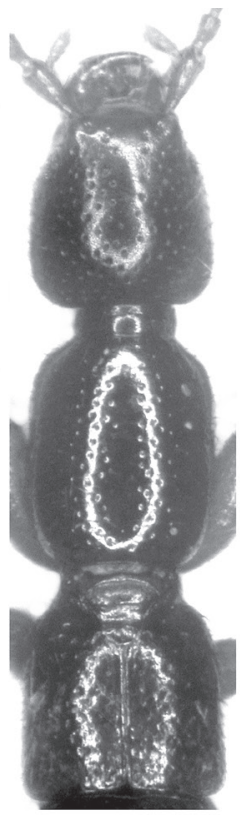

98

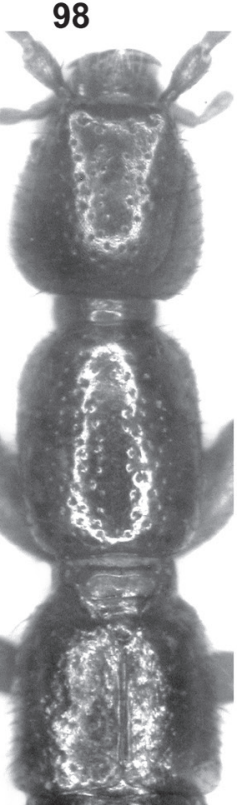

107

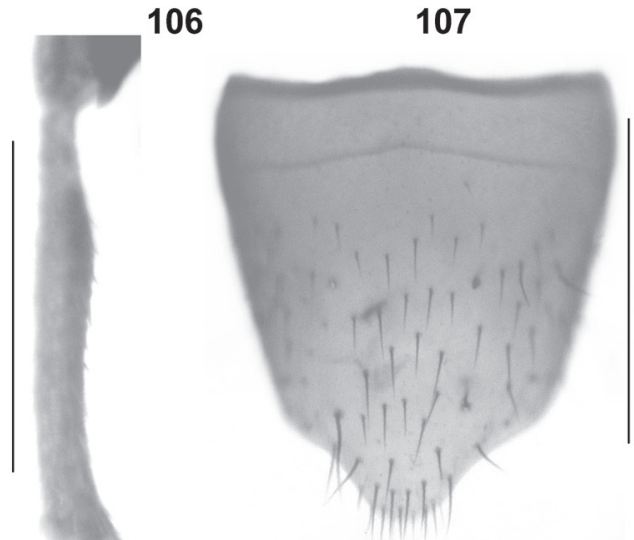

99

104

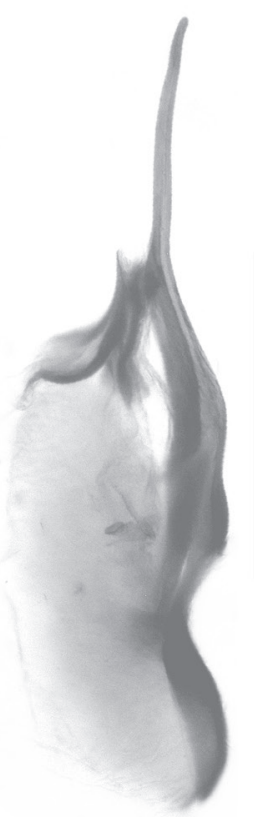

102

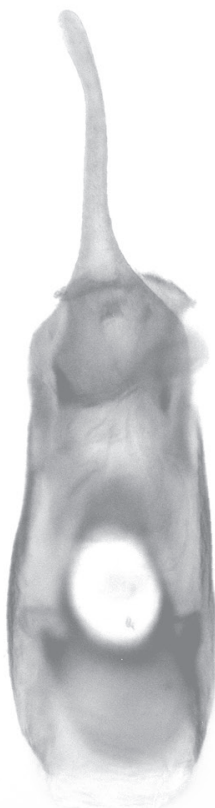

103

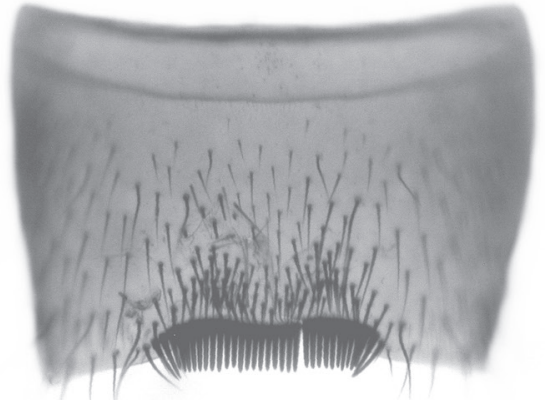

100
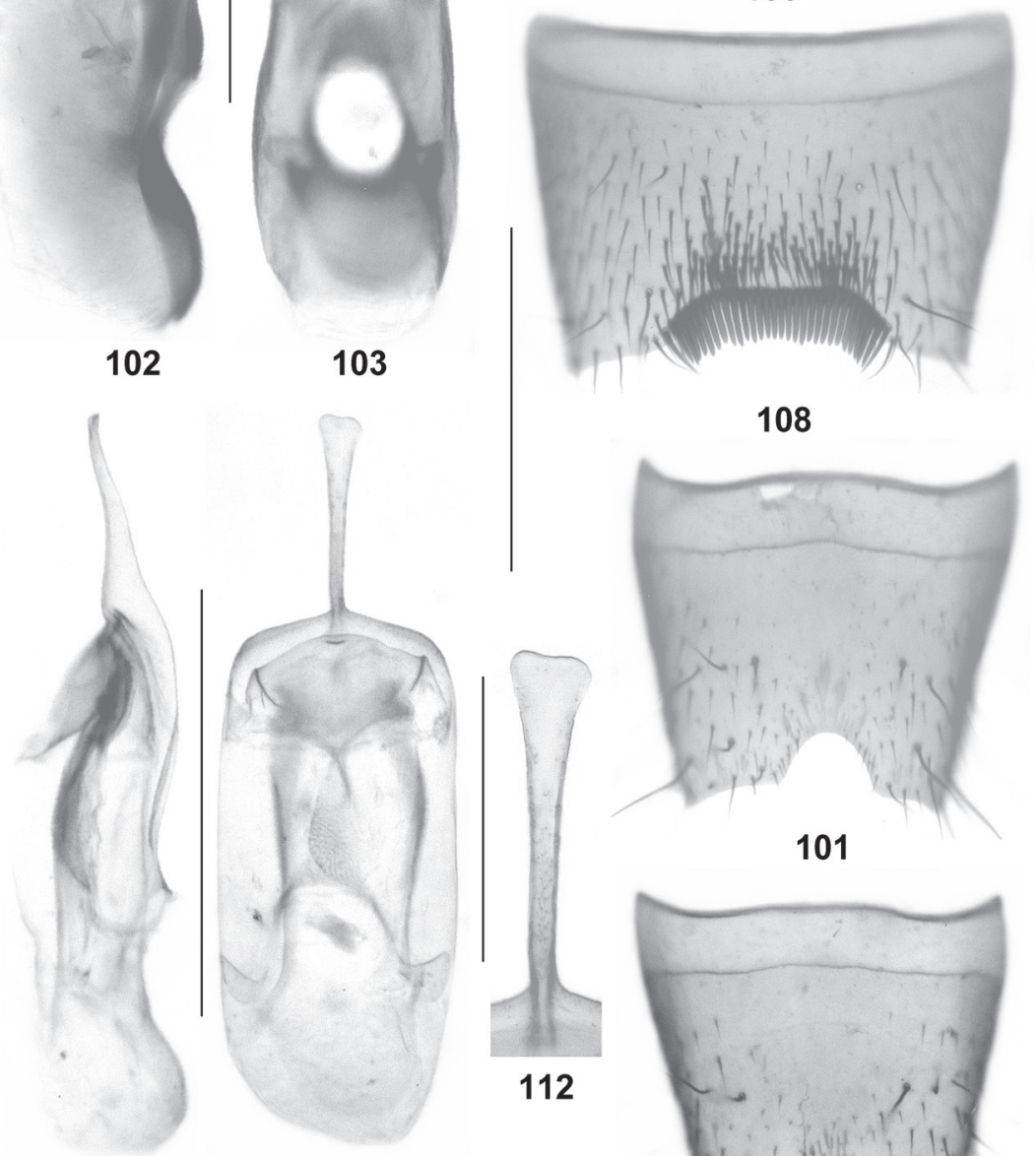

110

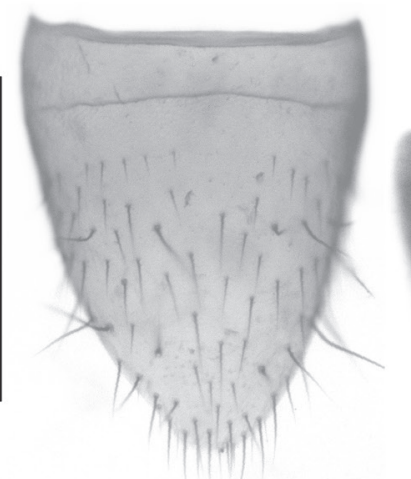

113

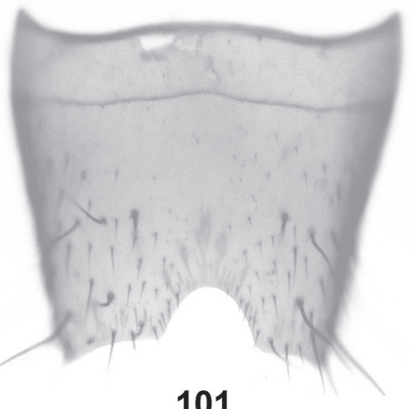

101

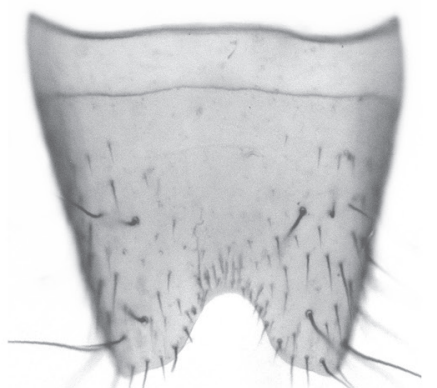

109
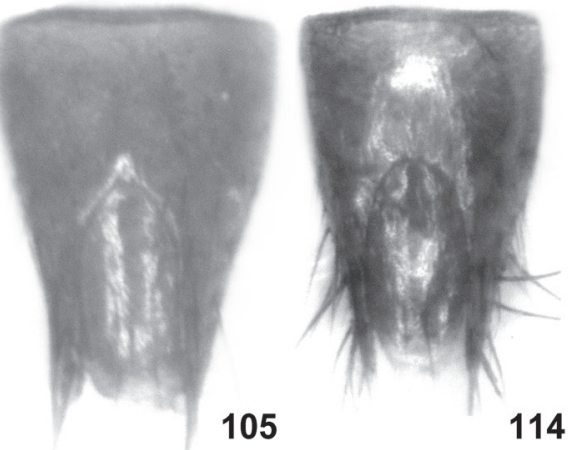

Figs 97-114: Lathrobium curvaculeatum sp.n. (97-105) and L. hebes sp. n. (106-114): habitus (97, 106); forebody (98, 107); male metatibia (99); male sternite VII $(100,108)$; male sternite VIII $(101,109)$; aedeagus in lateral and in ventral view (102-103, 110-111); female sternite VIII $(104,113)$; female tergites IX-X $(105,114)$; apical portion of ventral process of aedeagus in ventral view (112). Scale bars: 97-98, 106-107: $1.0 \mathrm{~mm}$; 99-105, 108-111, 113-114: $0.5 \mathrm{~mm}$; 112: $0.2 \mathrm{~mm}$. 
dimorphism; metatibia distinctly compressed in apical two-thirds in both sexes (Fig. 99); metafemora without sexual dimorphism.

Abdomen slightly broader than elytra; punctation distinct and moderately dense; interstices with shallow microsculpture; posterior margin of tergite VII without palisade fringe; posterior margin of tergite VIII convex.

$\mathrm{o}^{\top}$ : protarsomeres I-IV strongly dilated; sternite VII (Fig. 100) strongly transverse, with extensive, but shallow median impression, in posterior portion with transverse cluster of numerous black setae, posterior margin with broad and shallow posterior excision, margin of this excision with a comb of approximately 30 long palisade setae; sternite VIII (Fig. 101) approximately 1.2 times as broad as long, in anterior and median portion extensively without pubescence, posterior excision moderately deep, weakly asymmetric and of nearly semi-circular shape, lateral margins of this excision with a row of dense short setae; aedeagus (Figs 102-103) approximately $1.2 \mathrm{~mm}$ long and weakly asymmetric; ventral process basally broad and apically extending into a long spine-shaped process, apex of this process noticeably curved to the left in ventral view; dorsal plate broad, short, and apically weakly convex; internal sac without appreciable structures.

ㅇ: protarsomeres I-IV moderately dilated; sternite VIII (Fig. 104) 1.1 times as long as broad, posteriorly distinctly, convexly produced; tergite IX (Fig. 105) undivided in the middle, postero-lateral processes short, only slightly extending beyond apex of tergite $\mathrm{X}$; tergite $\mathrm{X}$ (Fig. 105) weakly convex in cross-section, of oval shape, and approximately 1.1 times as long as antero-median portion of tergite IX.

Comparative notes: Among the species of the L. pectinatum group with compressed metatibiae in both sexes, L. curvaculeatum is characterized by the relatively dark coloration, the shapes and chaetotaxy of the male sternites VII and VIII, and particularly by the shape of the ventral process of the aedeagus.

Distribution and natural history: The type locality is situated in the western Dhaulagiri range, Central Nepal (Map 2), at an altitude of $3250 \mathrm{~m}$.

\section{Lathrobium hebes sp. n.}

(Figs 106-114, Map 2)

Type material: Holotype $\sigma^{\star}$ [teneral]: "NEPAL SW Dhaulagiri, E Jaljala $3000 \mathrm{~m}$, 24.IX.12 lg. J. Schmidt, $28^{\circ} 30^{\prime} 49^{\prime \prime} \mathrm{N}, 83^{\circ} 15^{\prime} 18^{\prime \prime} \mathrm{E} / \mathrm{Holotypus}$ o $^{*}$ Lathrobium hebes sp. n., det. V. Assing 2013" (NME).

Paratypes: 1 \%: same data as holotype (NME); 1 : "NEPAL SW Dhaulagiri, E Jatiala [sic] 3000 m, 28³0'49"N, 83¹5'18"E, 24.IX.2012 leg. J. Schmidt” (cAss).
Etymology: The specific epithet (Latin, adjective: blunt) alludes to the apically blunt ventral process of the aedeagus.

Description: Body length 4.8-5.5 mm; length of forebody $2.4-2.8 \mathrm{~mm}$; male somewhat larger than females. Habitus as in Fig. 106. Coloration: forebody reddish; abdomen dark-brown to blackish-brown; legs and antennae reddish.

Head (Fig. 107) weakly oblong, 1.02-1.04 times as long as broad; punctation moderately dense and moderately coarse, sparser in median dorsal portion; interstices with distinct microreticulation. Eyes small, composed of approximately 10 ommatidia, approximately one-sixth as long as postocular region in dorsal view. Antenna $1.2-1.5 \mathrm{~mm}$ long.

Pronotum (Fig. 107) approximately 1.25 times as long as broad and about as broad as head; punctation similar to that of head; midline broadly impunctate; interstices without microsculpture.

Elytra (Fig. 107) approximately 0.6 times as long as pronotum; punctation shallow; interstices without distinct microsculpture. Hind wings completely reduced. Protarsomeres I-IV with moderately pronounced sexual dimorphism; metatibia weakly compressed in apical twothirds in both sexes. Metafemora without distinct sexual dimorphism.

Abdomen slightly broader than elytra; punctation distinct and moderately dense; interstices with shallow microsculpture; posterior margin of tergite VII without palisade fringe; tergite VIII with convex posterior margin.

$\sigma^{\star}$ : protarsomeres I-IV strongly dilated; sternite VII (Fig. 108) distinctly transverse, in postero-median portion with transverse cluster of long and stout black setae, posterior margin with broad, bisinuate, and shallow posterior excision, margin of this excision with a comb of approximately 30 long palisade setae; sternite VIII (Fig. 109) 1.1 times as broad as long, in median portion extensively without pubescence, posterior excision moderately deep, moderately broad, and anteriorly rounded, lateral margins of this excision with a row of dense short setae; aedeagus (Figs 110-111) $0.9 \mathrm{~mm}$ long and symmetric; ventral process basally broad and apically extending into a straight, spine-shaped, and apically truncate process in ventral view (Fig. 112); dorsal plate broad and very short; internal sac without appreciable structures.

\%: protarsomeres I-IV moderately dilated; sternite VIII (Fig. 113) 1.2 times as long as broad, posteriorly convexly produced; tergite IX (Fig. 114) with antero-median portion undivided in the middle and with short posterolateral processes; tergite X (Fig. 114) flattened and of oval shape, approximately 1.5 times as long as antero-median portion of tergite IX.

Comparative notes: Among the species of the L. pectinatum group, L. hebes is characterized particularly by the 
distinctive shape of the ventral process of the aedeagus and additionally by the shapes and chaetotaxy of the male sternites VII and VIII.

Distribution and natural history: The type locality is situated in the southwestern Dhaulagiri range, Central Nepal (Map 2), at an altitude of $3000 \mathrm{~m}$. The holotype is distinctly teneral.

\section{Lathrobium imberbe sp. $\mathrm{n}$.}

(Figs 115-122)

Type material: Holotype ơ: "NEPAL Prov. Karnali, Distr. Dolpa, Kagmara Lekh, Garpung Khola, 3000-3800 m 10.V.1995 leg. A. Weigel / Holotypus o Lathrobium imberbe sp. n., det. V. Assing 2013" (NME).

Paratypes: 1 운 same data as holotype (cAss); 1 운 "NEPAL, Prov. Karnali, Garpung Khola E Hurikot, Bachtal, 3800 m NN, 12.V.1995, leg.: J. Weipert” (NME).

Etymology: The specific epithet (Latin, adjective: without beard) alludes to the absence of a comb of palisade setae at the posterior margin of the male sternite VII.

Description: Body length 5.0-5.8 mm; length of forebody $2.6-2.9 \mathrm{~mm}$. Habitus as in Fig. 115. Coloration: whole body, including the appendages, reddish.

Head (Fig. 116) 1.03-1.05 times as long as broad; punctation sparse and moderately coarse; interstices on average distinctly broader than diameter of punctures, with shallow microreticulation. Eyes small, composed of approximately 10 ommatidia, approximately one-fifth as long as postocular region in dorsal view. Antenna 1.4-1.5 mm long.

Pronotum (Fig. 116) slender, 1.25-1.30 times as long as broad and about as broad as head; punctation similar to that of head; midline broadly impunctate; interstices without microsculpture.

Elytra (Fig. 116) rather broad, 0.56-0.60 times as long as pronotum; punctation distinct and moderately dense; interstices without distinct microsculpture. Hind wings completely reduced. Protarsomeres I-IV with weakly pronounced sexual dimorphism.

Abdomen only slightly broader than elytra; punctation not very fine and moderately dense; interstices with shallow microsculpture; posterior margin of tergite VII without palisade fringe; posterior margin of tergite VIII weakly convex, without appreciable sexual dimorphism.

$\mathrm{o}^{\mathrm{T}}$ : protarsomeres I-IV moderately dilated; sternite VII (Fig. 117) distinctly transverse and with sparse unmodified pubescence, posterior margin broadly concave; sternite VIII (Fig. 118) as long as broad, in the middle with extremely short, fine, and sparse pubescence, posterior excision moderately deep (approximately 0.2 times as deep as length of sternite) and slightly asymmetric; aedeagus (Figs 119-120) $1.25 \mathrm{~mm}$ long and apically weakly asymmetric; ventral process shaped like a stout spine; dorsal plate short and lamellate, in lateral view very weakly curved; internal sac without sclerotized structures.

क: protarsomeres I-IV moderately dilated, slightly less so than in male; sternite VIII (Fig. 121) approximately 1.15 times as long as broad and with moderately sparse pubescence, posterior margin strongly convex; tergite IX (Fig. 122) undivided in the middle, postero-lateral processes short and apically acute, slightly extending beyond apex of tergite X; tergite X (Fig. 122) flat, of oval shape, and distinctly longer than antero-median portion of tergite IX.

Comment and comparative notes: According to the species group concept proposed in Assing (2012), L. imberbe would have to be attributed to the L. aculeatum group, which previously included two species from Central Nepal, L. aculeatum CoIfFAIt, 1982 and L. spiculatum Assing, 2012. These two species probably represent adelphotaxa and are mainly distinguished from the species of the L. pectinatum group by the absence of combs of palisade setae and a more slender aedeagus. Regarding the morphology of the aedeagus, L. imberbe is intermediate between the species of the L. pectinatum group and those previously attributed to the L. aculeatum group. With respect to other external and male sexual characters the species of both groups are very similar. These observations and supporting zoogeographic evidence make it seem likely that the absence of combs of palisade setae at the posterior margin of the male sternite VII is actually a secondary reduction that may have occurred convergently. Consequently, L. imberbe, L. aculeatum, and L. spiculatum are assigned to the L. pectinatum group.

Lathrobium imberbe is readily distinguished from L. aculeatum and L. spiculatum, with which it shares the unmodified chaetotaxy of the male sternite VII, by the different morphology of the aedeagus. Most other species of the L. pectinatum group have conspicuous combs of palisade setae on the male sternite VII. For illustrations of the previously described representatives of the L. pectinatum group see Assing (2012).

Distribution and natural history: The species was found in two geographically close localities in the Garpung Khola valley in Dolpa District, Karnali Province, West Nepal (Map 2). One paratype was collected at an altitude of $3800 \mathrm{~m}$, the remaining type specimens at an elevation between 3000 and $3800 \mathrm{~m}$, together with an unnamed species (Lathrobium sp. 1; see below).

\section{Lathrobium aculeatum CoIfFAIT, 1982}

(Figs 123-129, Map 2)

Material examined: Nepal: $22 \sigma^{\star} \sigma^{x}, 6$ ㅇ ㅇ [partly teneral], W-Dhaulagiri, N-slope of Jungla pass, $28^{\circ} 52^{\prime} \mathrm{N}, 82^{\circ} 58^{\prime} \mathrm{E}$, 3400-3800 m, 12.IX.2012, leg. Schmidt (NME, cAss); $4 o^{x} o^{x}, 4$ 우 우 [partly teneral], W-Dhaulagiri, above Tara- 

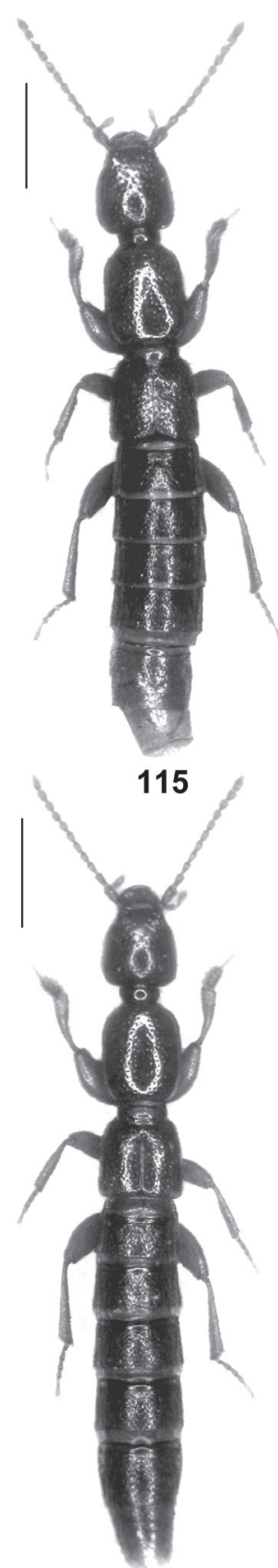

123

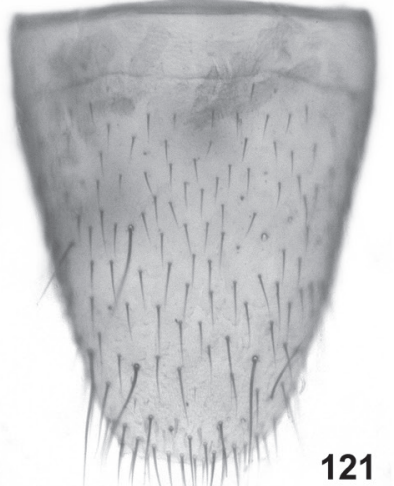

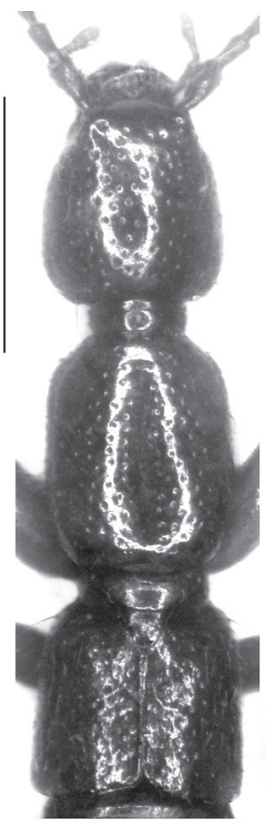

116

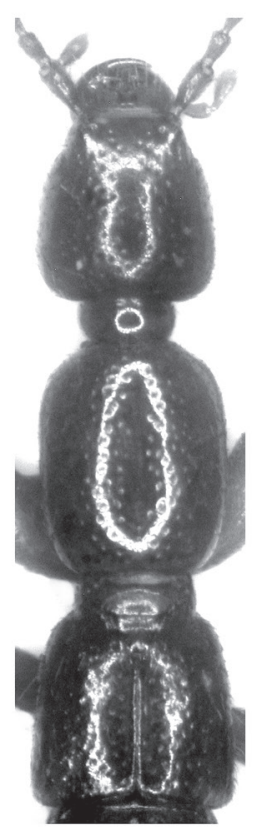

124

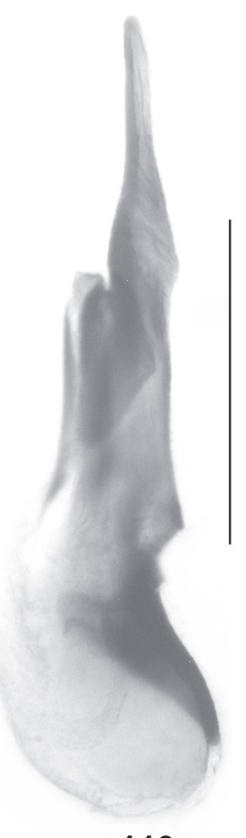

119

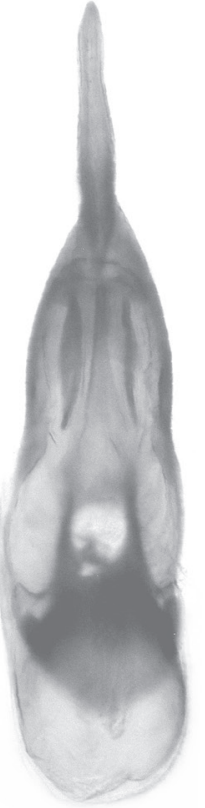

120

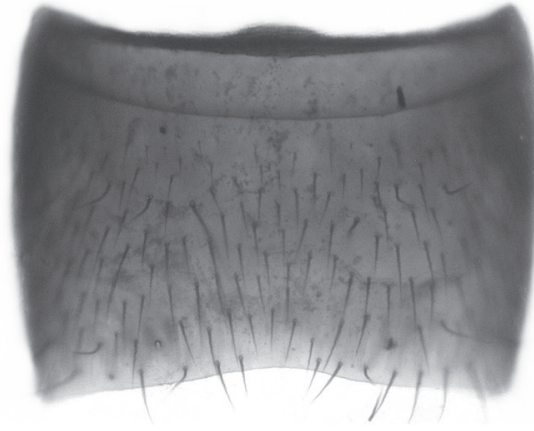

117

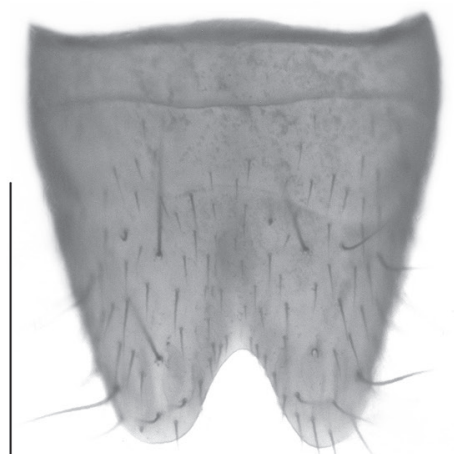

118

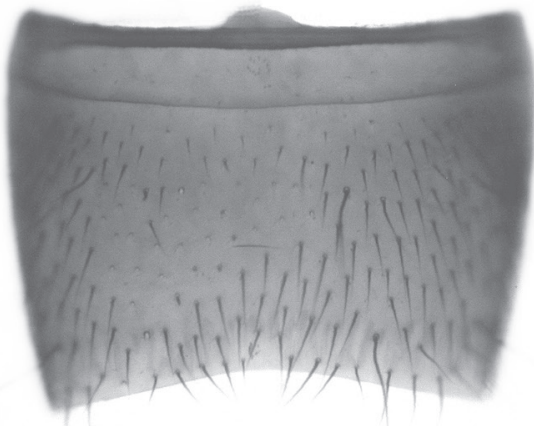

125

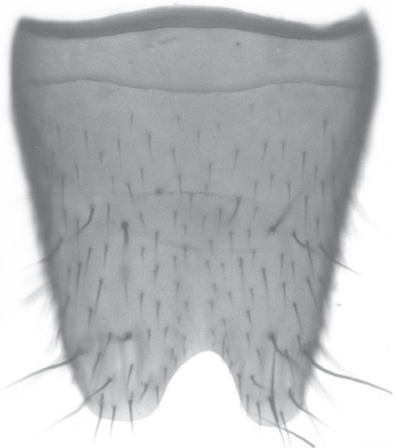

126

\section{2}

127

128
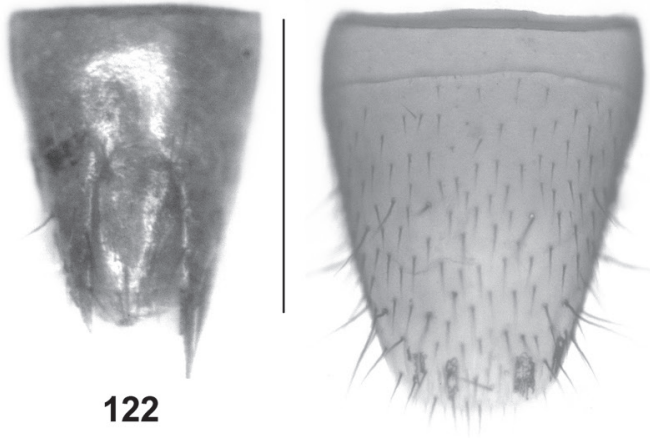

129

Figs 115-129: Lathrobium imberbe sp. n. (115-122) and L. aculeatum CoIfFAIT (123-129): habitus (115, 123); forebody (116, 124); male sternite VII $(117,125)$; male sternite VIII $(118,126)$; aedeagus in lateral and in ventral view $(119-120,127-128)$; female sternite VIII $(121,129)$; female tergites IX-X (122). Scale bars: 115-116, 123-124: 1.0 mm; 117-122, 125-129: 0.5 mm. 
kot, $28^{\circ} 51^{\prime} \mathrm{N}, 82^{\circ} 59^{\prime} \mathrm{E}, 3050 \mathrm{~m}, 10 . \mathrm{IX} .2012$, leg. Schmidt (NME, cAss).

Comment: The redescription in Assing (2012) is based only on two type specimens in rather poor condition. The above specimens render a more accurate redescription and better illustrations possible.

Redescription: Body length 5.0-6.8 mm; length of forebody $2.3-2.9 \mathrm{~mm}$; size subject to sexual dimorphism (males larger than females). Habitus as in Fig. 123. Coloration: body reddish, with the abdomen often somewhat darker; legs dark-yellowish; antennae reddish.

Head (Fig. 124) 1.03-1.05 times as long as broad; punctation rather sparse and moderately coarse; interstices on average distinctly broader than diameter of punctures, with distinct microreticulation. Eyes small, composed of approximately 10 ommatidia, approximately one-sixth as long as postocular region in dorsal view. Antenna $1.3-1.5 \mathrm{~mm}$ long.

Pronotum (Fig. 124) approximately 1.25 times as long as broad and 1.00-1.07 times as broad as head; punctation similar to that of head, but slightly denser; midline broadly impunctate; interstices without microsculpture. Elytra (Fig. 124) approximately 0.6 times as long as pronotum; punctation fine and rather sparse; interstices without distinct microsculpture. Hind wings completely reduced. Protarsomeres I-IV with moderately pronounced sexual dimorphism; metatibiae and -femora unmodified.

Abdomen slightly broader than elytra; punctation distinct and rather dense, sparser on tergite VIII; interstices with shallow microsculpture; posterior margin of tergite VII without palisade fringe; posterior margin of tergite VIII convex.

$0^{\lambda}$ : protarsomeres I-IV distinctly dilated; sternite VII (Fig. 125) moderately transverse, with unmodified pubescence and with weakly concave posterior margin; sternite VIII (Fig. 126) approximately 1.07 times as long as broad, pubescence unmodified, posterior excision moderately deep and nearly U-shaped; aedeagus (Figs 127-128) approximately $1.15 \mathrm{~mm}$ long; ventral process extended into a long and slender spine, this spine weakly asymmetric and basally with ventral carina; dorsal plate short and membranous; internal sac without sclerotized structures.

\%: protarsomeres I-IV moderately dilated; sternite VIII (Fig. 129) approximately 1.25 times as long as broad and with convex posterior margin; tergite IX undivided in the middle, postero-lateral processes short and apically acute, barely extending beyond apex of tergite X; tergite $\mathrm{X}$ weakly convex in cross-section, of oval shape, and approximately 1.25 times as long as antero-median portion of tergite IX.

Distribution and natural history: Lathrobium aculeatum is known from three geographically close localities in the western Dhaulagiri range (Map 2). The above spec- imens, several of them teneral, were found close to the type locality, which is situated at approximately $28^{\circ} 51^{\prime} \mathrm{N}$, $83^{\circ} 00^{\prime} \mathrm{E}$. They were collected at an altitude of $3050 \mathrm{~m}$ and between 3400 and $3800 \mathrm{~m}$.

\section{Lathrobium plicatum sp. $\mathrm{n}$.} (Figs 130-137, Map 2)

Type material: Holotype $\sigma^{\star}:$ "NEPAL W Dhaulagiri, env. Dhule, 3400-3500 m, 28 $42^{\circ} 10^{\prime \prime} \mathrm{N}, 82^{\circ} 55^{\prime} 53^{\prime \prime E}$, 18.IX.2012, leg. J. Schmidt / Holotypus $0^{\star}$ Lathrobium plicatum sp. n., det. V. Assing 2013" (NME).

Paratypes: $10^{\star}, 4$ 우 : same data as holotype (NME, cAss).

Etymology: The specific epithet is the past participle of the Latin verb plicare (to coil up) and alludes to the conspicuous shape of the ventral process of the aedeagus in lateral view.

Description: Body length 5.0-6.4 mm; length of forebody $2.3-2.7 \mathrm{~mm}$; body size subject to sexual dimorphism, males larger than females. Habitus as in Fig. 130. Coloration: forebody reddish; abdomen dark-brown; legs dark-yellowish; antennae reddish.

Head (Fig. 131) 1.02-1.07 times as long as broad; punctation sparse and moderately coarse; interstices distinctly broader than diameter of punctures, with extremely shallow, almost obsolete microreticulation. Eyes small, composed of approximately 10 ommatidia, approximately one-sixth as long as postocular region in dorsal view. Antenna 1.3-1.4 mm long.

Pronotum (Fig. 131) approximately 1.25 times as long as broad and 1.00-1.03 times as broad as head; punctation similar to that of head; midline broadly impunctate; interstices without microsculpture.

Elytra (Fig. 131) short, 0.55-0.57 times as long as pronotum; punctation fine and rather sparse; interstices without distinct microsculpture. Hind wings completely reduced. Protarsomeres I-IV with pronounced sexual dimorphism; metatibiae compressed in apical twothirds.

Abdomen slightly broader than elytra; punctation distinct and dense; interstices with shallow microsculpture; posterior margin of tergite VII without palisade fringe; posterior margin of tergite VIII very weakly convex, nearly truncate.

$0^{\star}$ : protarsomeres I-IV strongly dilated; sternite VII (Fig. 132) distinctly transverse and with very weakly modified pubescence, posterior margin shallowly V-shaped; sternite VIII (Fig. 133) approximately 1.07 times as broad as long, with unmodified pubescence, posterior excision moderately deep and slightly asymmetric, nearly U-shaped; aedeagus (Figs 134-135) approximately $1.4 \mathrm{~mm}$ long; ventral process of highly distinctive shape, apically very long and slender, coiled in lateral view; dorsal plate membranous, not sclerotized; internal sac without sclerotized structures. 


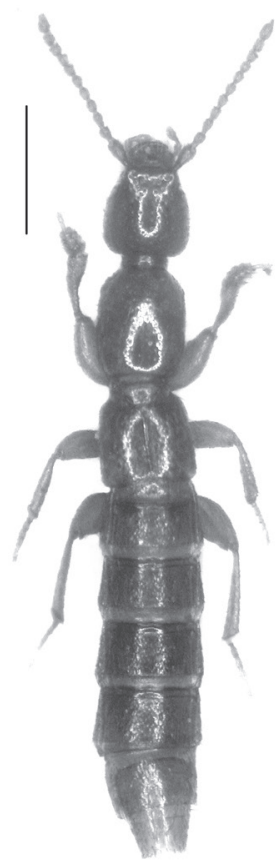

130

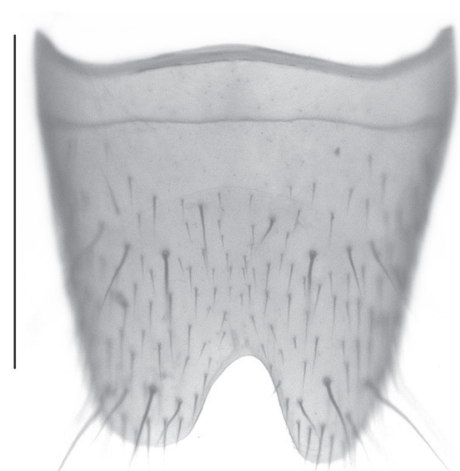

133

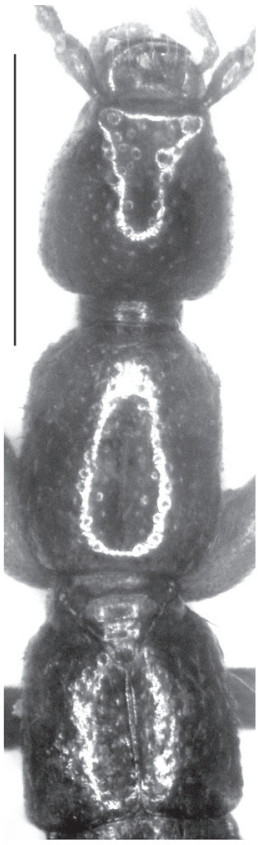

131

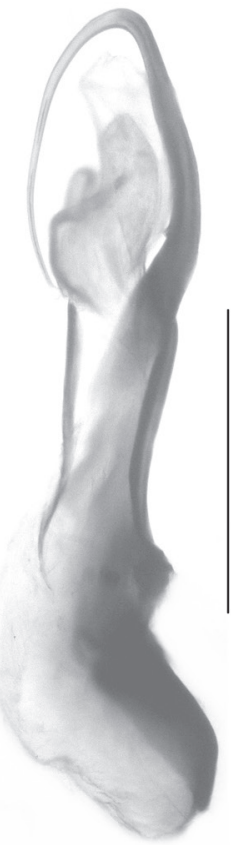

134

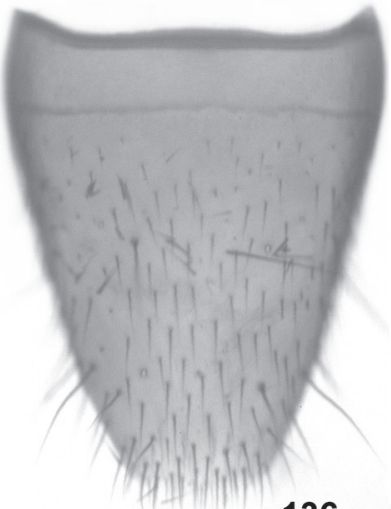

136

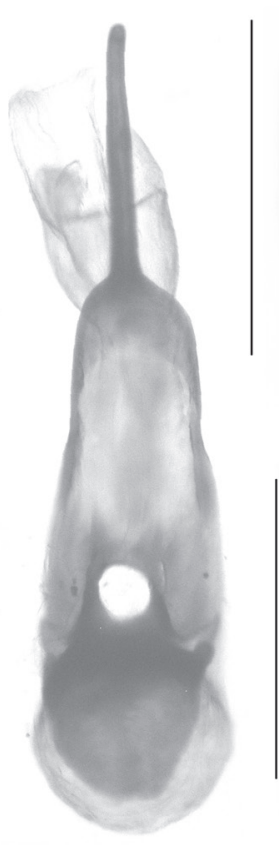

135

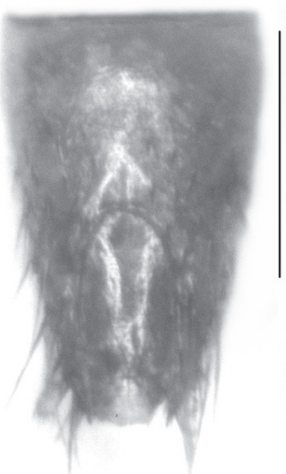

137

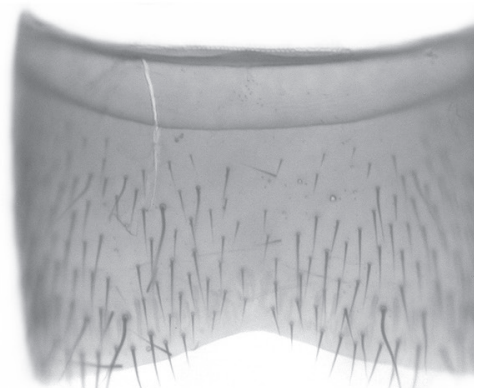

132

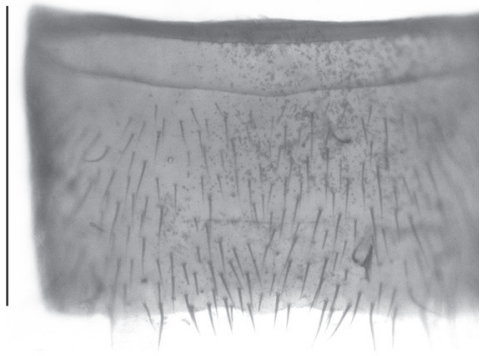

138

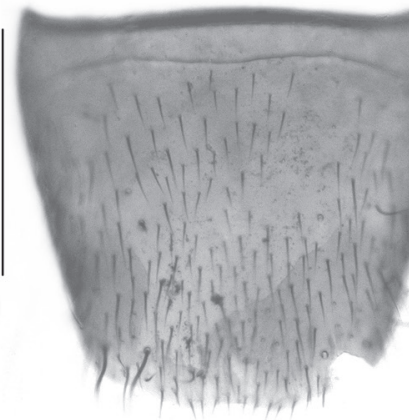

139

Figs 130-139: Lathrobium plicatum sp. n. (130-137) and L. ascendens sp. n. (138-139): habitus (130); forebody (131); male sternite VII $(132,138)$; male sternite VIII (133); aedeagus in lateral and in ventral view (134-135); female sternite VIII (136, 139); female tergites IX-X (137). Scale bars: 130-131: $1.0 \mathrm{~mm}$; 132-139: $0.5 \mathrm{~mm}$.

†: protarsomeres I-IV moderately dilated, much less so than in male; sternite VIII (Fig. 136) approximately 1.23 times as long as broad, strongly tapering posteriad and with truncate posterior margin; tergite IX (Fig. 137) undivided in the middle, postero-lateral processes short and apically acute, barely extending beyond apex of tergite X; tergite X (Fig. 137) weakly convex in crosssection, of oval shape, and approximately as long as antero-median portion of tergite IX.

Comparative notes: Like the preceding species, L. plicatum belongs to the L. pectinatum group. It differs from all its congeners particularly by the highly distinctive shape of the ventral process of the aedeagus, also by the shape of the male sternite VII, from most species of the L. pectinatum group additionally by the nearly obsolete microsculpture of the head.
Distribution and natural history: The type locality is situated in the western Dhaulagiri range (Map 2) at an altitude of 3400-3500 m. Most of the type specimens are at least slightly teneral.

\section{Unnamed species}

The following species remain unnamed, as they are represented exclusively by females.

\section{Lathrobium sp. 1}

Material examined: 2 o 9 : “NEPAL Prov. Karnali, Distr. Dolpa, Kagmara Lekh, Garpung Khola, 3000-3800 m 10.V.1995 leg. A. Weigel" (NME, cAss); 2 o $~:$ same data, but leg Hartmann (NME); 1 \%: "NEPAL Prov. Karnali, 
Distr. Dolpa, Kagmara Lekh, Bach am Steilhang 3800 m 13.V.1995 leg. A. Weigel” (NME); 2 우 ㅇ․ "NEPAL Prov. Karnali, Distr. Dolpa, Kagmara Lekh, 3800 m NN, leg. M. Hartmann, 11.V.1995, Bodenstreugesiebe" (NME, cAss); 1 ㅇ: "NEPAL Prov. Karnali, Distr. Dolpa, Kagmara Lekh, Garpung Khola, 3800-3000 m 14.V.1995 leg. A. Weigel” (NME).

Comment: The above females were collected at and near the type locality of L. imberbe. They are distinguished from this species by slightly smaller body size, the slightly different shape of the female sternite VIII, the longer antero-median portion of the female tergite IX, and by the smaller female tergite $\mathrm{X}$.

\section{Lathrobium sp. 2}

Material examined: 2 q ㅇ: "NEPAL, Dhaulagiri, SE slope, SW slope of Lete pass, 13.V.2002, 2700-3000 m NN, leg. J. Schmidt" (NME); 1 \%: "NEPAL, Kali Gandaki valley, upper Lete, 19.V.2002, $2800 \mathrm{~m}$ NN, leg. J. Schmidt" (NME).

\section{Lathrobium sp. 3}

Material examined: 1 : "NEPAL, Seti/Bajura, $18 \mathrm{~km}$ W Simikot, Sankha La-Kuwadi Kh. / 46-4000 m, 2954'40"N, $81^{\circ} 38^{\prime} 49^{\prime \prime E}, 3$.VII.2001, leg. A. Weigel HF, mt. meadows \& pastures" (NME).

\section{Lathrobium sp. 4}

Material examined: 5 ㅇ ㅇ: "NEPAL, Manaslu Mts., Dudh Pokhari Lekh, upper Dordi Khola Valley, 15.-17.IV.2003, 2600-2300 m NN, leg. J. Schmidt” (NME); 1 ㅇ: "NEPAL, Manaslu Mts., Dudh Pokhari Lekh, upper Deorali Danda, 19.IV.2003, 3200 m NN, leg. J. Schmidt” (NME).

\subsection{Species from China}

\section{Lathrobium glabrimpressum sp. n. (Figs 140-148)}

Type material: Holotype $0^{*}$ : "CHINA: P.R. CHINA, Yunnan, E slope N Gaoligongshan, N27²6.8' E098 33.1', 12-15.vi.2009, 2000-3000 m, sifting1-7, V. Grebennikov / Holotypus $0^{\star}$ Lathrobium glabrimpressum sp. n., det. V. Assing 2013" (CAS).

Paratypes: 1 ㅇ: same data as holotype (cSme); $10^{\text {* }}$ : "CHINA: P.R. CHINA, Yunnan, E slope N Gaoligongshan, N27²7'22.1" E098 32'17.7", 24.v.2010, 3027 m, sifting21, V. Grebennikov" (cAss).

Etymology: The specific epithet is an adjective composed of the Latin adjectives glaber (bald, without hair) and impressus (impressed). It alludes to the non-pubescent impression of the male sternite VIII.

Description: Relatively small species; body length 5.0-5.5 mm; length of forebody $2.4-2.7 \mathrm{~mm}$. Habitus as in Fig. 140. Coloration: forebody reddish-brown to brown; abdomen dark-brown to blackish-brown; legs dark-yellowish; antennae reddish.

Head (Fig. 141) 1.05-1.08 times as long as broad, more or less distinctly dilated behind eyes; punctation sparse and moderately coarse; interstices with microreticulation, distinctly broader than diameter of punctures. Eyes weakly projecting from lateral contours of head and small, approximately one-fourth as long as postocular region in dorsal view and composed of little more than 20 ommatidia. Antenna 1.4-1.5 mm long.

Pronotum (Fig. 141) of rather variable shape, 1.201.28 times as long as broad and as broad as, or slightly broader than, head; punctation similar to that of head, but slightly denser; impunctate midline moderately broad; interstices without microsculpture.

Elytra (Fig. 141) short, 0.56-0.60 times as long as pronotum, very weakly dilated posteriad; humeral angles moderately marked; punctation sparse, shallower than that of head and pronotum; interstices without microsculpture. Hind wings completely reduced. Protarsomeres I-IV with moderate sexual dimorphism.

Abdomen approximately 1.05 times as broad as elytra; punctation fine and dense; interstices with microsculpture; posterior margin of tergite VII without palisade fringe; tergite VIII with weakly pronounced sexual dimorphism.

$\sigma^{\top}$ : protarsomeres I-IV distinctly dilated; tergite VIII with weakly convex posterior margin; sternite VII (Fig. 142) distinctly transverse, posteriorly with shallow median impression of triangular shape, this impression with cluster of long black setae on either side, posterior margin broadly concave; sternite VIII (Fig. 143) oblong, approximately 1.08 times as long as broad and with oblong median impression posteriorly, this impression without setae in the middle and laterally with a cluster of long black setae on either side, posterior excision U-shaped and approximately 0.15 times as deep as length of sternite; aedeagus (Figs 144-145) approximately $0.9 \mathrm{~mm}$ long and symmetric; ventral process slender, curved, and apically acute in lateral view; dorsal plate with distinctly sclerotized, moderately long, basally broad, and apically spine-shaped apical portion (Fig. 146), and with short membranous basal portion; internal sac without distinct spines, but with long dark membranous structures.

i : protarsomeres I-IV moderately dilated, slightly less so than in male; posterior margin of tergite VIII more strongly convex than in male; sternite VIII (Fig. 147) distinctly oblong and strongly convex posteriorly; tergite IX (Fig. 148) with rather long and undivided antero-median portion and with slender postero-lateral processes; tergite X (Fig. 148) long, slender, moderately 


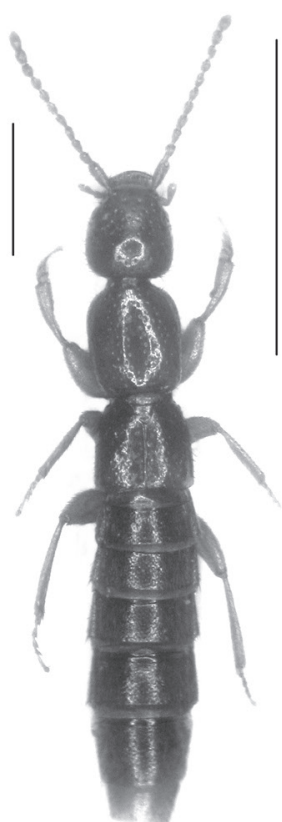

140

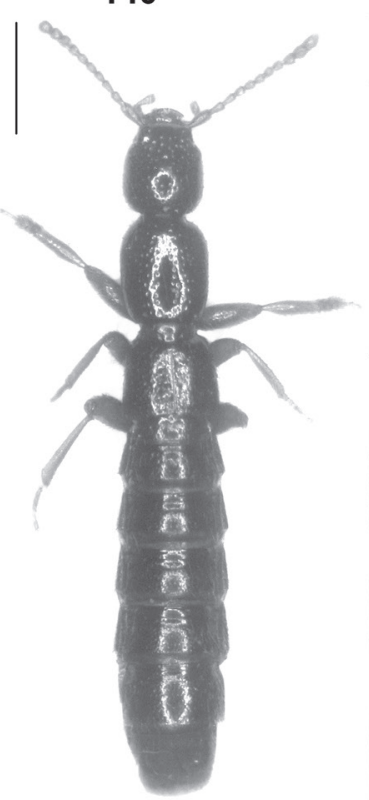

149

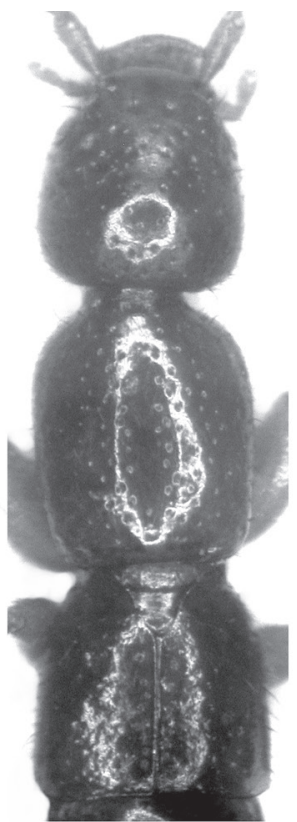

141

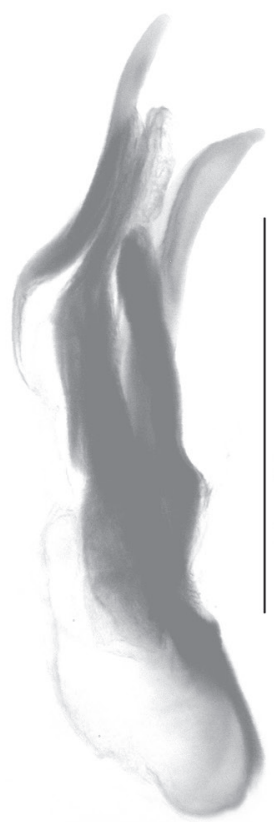

144

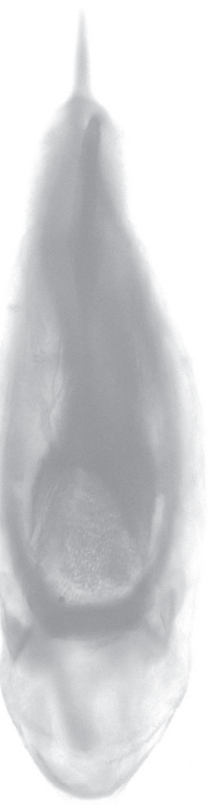

145

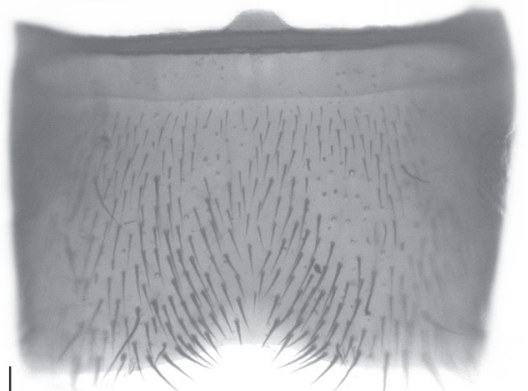

142

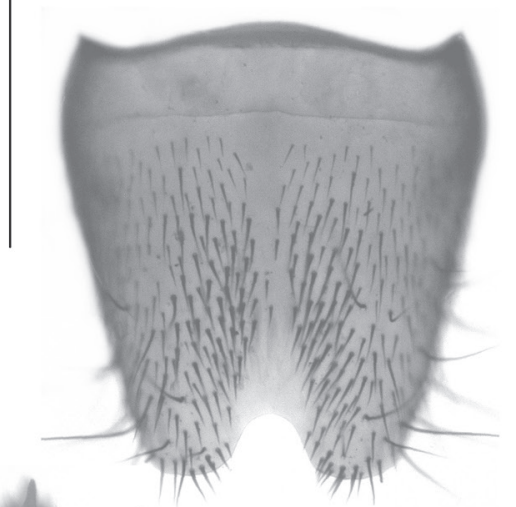

143

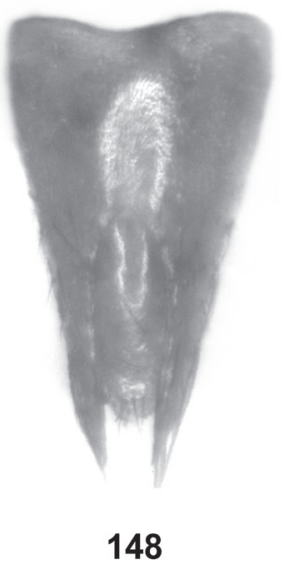

153

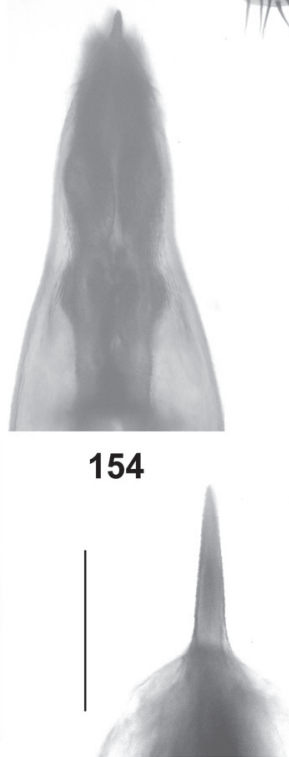

146

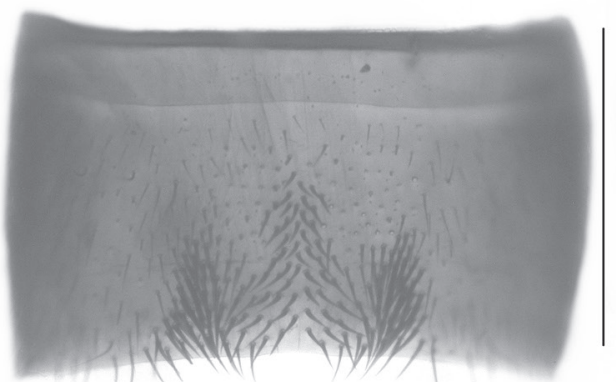

151
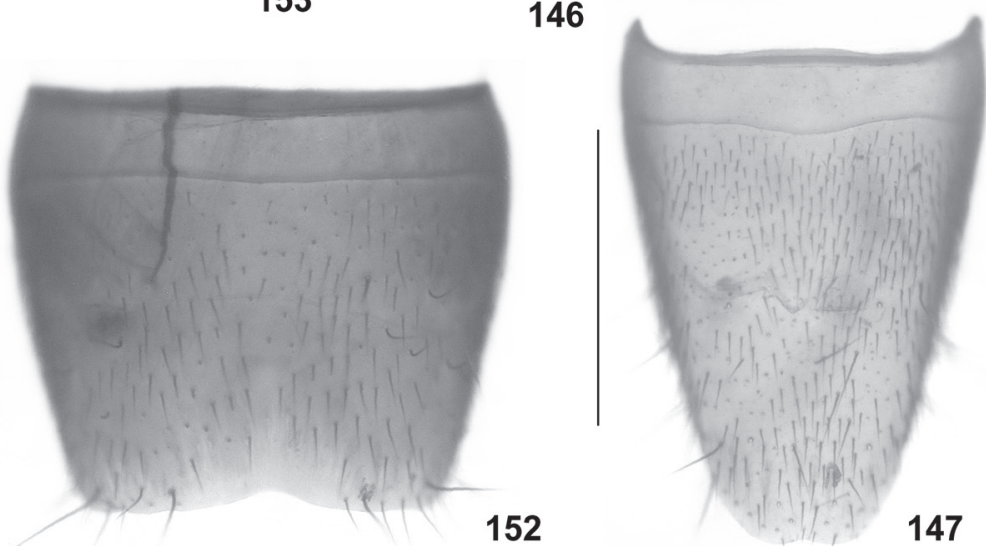

Figs 140-154: Lathrobium glabrimpressum sp. n. (140-148) and L. smetanai sp. n. (149-154): habitus (140, 149); forebody (141, $150)$; male sternite VII $(142,151)$; male sternite VIII $(143,152)$; aedeagus in lateral and in ventral view $(144-145,153)$; apex of dorsal plate of aedeagus in dorsal view (146); female sternite VIII (147); female tergites IX-X (148); apical portion of aedeagus in ventral view (154). Scale bars: 140-141, 149-150: 1.0 mm; 142-145, 147-148, 151-154: 0.5 mm; 146: 0.1 mm. 
convex in cross-section anteriorly, and noticeably longer than antero-median portion of tergite IX.

Comparative notes: Lathrobium glabrimpressum is distinguished from all other species recorded from the Gaoligong Shan by the distinctive morphology of the aedeagus, as well as by the shapes and chaetotaxy of the male sternites VII and VIII, from most species also by the undivided antero-median portion of the female tergite IX. For illustrations of other species known from the Gaoligong Shan see Assing (2013b) and Watanabe \& XiaO $(1997,2000)$. Closer phylogenetic affiliations to any of the species and species groups previously recorded from Yunnan (Assing 2013b) are not evident.

Distribution and natural history: The type material was sifted in two geographically close localities in the northern Gaoligong Shan. One of the paratypes was collected at an elevation of approximately $3030 \mathrm{~m}$, the other two specimens at an altitude between 2000 and $3000 \mathrm{~m}$.

\section{Lathrobium smetanai sp. n.}

(Figs 149-154)

Type material: Holotype $0^{*}$ : "CHINA, Gansu, Dalijia Shan [ca. 35 $34^{\prime} \mathrm{N}, 102^{\circ} 44^{\prime} \mathrm{E}$ ], $46 \mathrm{~km}$ W Linxia, $2980 \mathrm{~m}$, 10.VII.1994, A. Smetana [C5] / Holotypus ơ Lathrobium smetanai sp. n., det. V. Assing 2013” (cAss).

Etymology: This species is dedicated to Aleš Smetana, one of the foremost taxonomists of Staphylinidae of all times and collector of the holotype.

Description: Body length $6.4 \mathrm{~mm}$; length of forebody $2.7 \mathrm{~mm}$. Habitus as in Fig. 149. Coloration: body black; legs and antennae reddish.

Head (Fig. 150) small in relation to body and distinctly oblong, 1.1 times as long as broad; punctation sparse and moderately coarse; interstices without microreticulation, distinctly broader than diameter of punctures. Eyes weakly projecting from lateral contours of head and of moderate size, approximately one-third as long as postocular region in dorsal view and composed of approximately 40 ommatidia. Antenna $1.5 \mathrm{~mm}$ long.

Pronotum (Fig. 150) 1.23 times as long as broad and 1.08 times as broad as head; punctation similar to that of head; midline broadly impunctate; interstices without microsculpture.

Elytra (Fig. 150) broad and short, 0.58 times as long as pronotum, very weakly dilated posteriad; humeral angles moderately marked; punctation moderately sparse and fine, but distinct and defined; interstices without microsculpture. Hind wings completely reduced. Legs short. Abdomen large in relation to forebody, approximately 1.2 times as broad as elytra; punctation fine and rather sparse; interstices with fine transverse microsculpture; posterior margin of tergite VII without palisade fringe. $\sigma^{\top}$ : protarsomeres I-IV moderately strongly dilated; tergite VIII with weakly convex posterior margin; sternite VII (Fig. 151) strongly transverse, posteriorly with shallow median impression with cluster of distinctly modified short and stout black setae, on either side of this impression with additional cluster of stout and long black setae, posterior margin broadly concave; sternite VIII (Fig. 152) distinctly transverse, approximately 1.2 times as broad as long, aside from scattered long black setae with very short and rather sparse pubescence, posterior margin very weakly concave in the middle; aedeagus (Figs 153-154) $1.25 \mathrm{~mm}$ long and asymmetric; ventral process slender in lateral view and apically acute; dorsal plate with lamellate apical portion and without noticeable basal portion; internal sac with long dark structures, but without sclerotized spines.

o : unknown

Comparative notes: Based on the external (small oblong head without microsculpture; short legs; large abdomen with transverse microsculpture and sparse fine punctation) and the male sexual characters (shapes and chaetotaxy of the male sternites VII and VIII; morphology of the aedeagus), L. smetanai clearly belongs to the L. lentum group (see Assing 2013a), which previously included only L. lentum Assing, 2013 from the environs of Songpan in northern Sichuan. It is distinguished from this species by smaller body size (L. lentum: length of male forebody: 3.0-3.4 mm), the reddish legs (L. lentum: legs dark-brown), the different chaetotaxy of the male sternite VII, the sparser pubescence and more weakly concave posterior margin of the male sternite VIII, and by the smaller and differently shaped aedeagus. For illustrations of L. lentum see Assing (2013a).

Distribution and natural history: The type locality is situated in the Dalijia Shan in the southwest of Gansu province, close to the border with Qinghai province, at an altitude of nearly $3000 \mathrm{~m}$. The holotype was sifted from wet debris and moss among lush vegetation in pastures with willow bushes (SMETANA pers. comm.).

\section{Acknowledgements}

I am indebted to the colleagues indicated in the material section for the loan of material under their care. In particular, I am grateful to Aleš Smetana for the generous gift of the holotype of L. smetanai. Joachim Schmidt (Greifswald) provided geographic information on the Kali Danda in Nepal. Lee Herman cross-checked the new names against his unpublished world catalogue of Paederinae. Benedikt Feldmann (Münster) proof-read the manuscript. 


\section{References}

Assing, V. 2010: On the Lathrobiina of Taiwan (Coleoptera: Staphylinidae: Paederinae). - Beiträge zur Entomologie, Keltern 60 (2): 301-361.

Assing, V. 2012: A revision of the Lathrobium species of the Himalaya (Coleoptera: Staphylinidae: Paederinae). - Bonn Zoological Bulletin 61 (2): 142-209.

Assing, V. 2013a: On the Lathrobium fauna of China I. The species of the Qinling Shan, the Daba Shan, and adjacent mountain ranges (Coleoptera: Staphylinidae: Paederinae). - Bonn Zoological Bulletin 62 (1): 1-29.

Assing, V. 2013b: On the Lathrobium fauna of China V. New species and additional records from Yunnan (Coleoptera: Staphylinidae: Paederinae). - Contributions to Entomology, Beiträge zur Entomologie 63 (1) (2013): 53-128.

Assing, V. 2013c: Six new species and additional records of Lathrobium from the Palaearctic region (Coleoptera: Staphylinidae: Paederinae). - Linzer Biologische Beiträge 45 (1): 247-266.

Assing, V. 2013d: On the Lathrobium fauna of Japan (Coleoptera: Staphylinidae: Paederinae). - Linzer Biologische Beiträge 45 (2): 1615-1641.

Assing, V. 2013e: New species and records of Lathrobium from China and Nepal (Coleoptera: Staphylinidae: Paederinae). - Linzer Biologische Beiträge 45 (2): 1643-1655.

Assing, V. 2013f: Two new genera of Lathrobiina from the East Palaearctic region (Coleoptera: Staphylinidae: Paederinae). - Contributions to Entomology, Beiträge zur Entomologie 63 (2): 219-239.
Coiffait, H. 1981: Un Lathrobium méconnu de la faune caucasienne. - Nouvelle Revue d'Entomologie 11 (2): 129-131.

Peng, Z.; LI, L.-Z. \& ZhaO, M.-J. 2014: Seventeen new species and additional records of Lathrobium (Coleoptera, Staphylinidae) from mainland China. Zootaxa 3780 (1): 1-35.

Smetana, A. 2004: Subfamily Paederinae Fleming, 1821. - In: Löbl, I. \& Smetana, A. (eds), Catalogue of Palaearctic Coleoptera. Volume 2. Hydrophiloidea - Histeroidea - Staphylinoidea. - Apollo Books, Stenstrup: 579-624.

Solodovnikov, A. YU. 2001: Revision of the little-known apterous Paederinae (Coleoptera: Staphylinidae) from "Circassia" (North-Western Caucasus), with description of Lathrobium (Lobrathium) bettae sp. n. - Russian Entomological Journal 10 (1): 1-11.

Watanabe, Y. \& Xiao, N.-N. 1997: New species of apterous Lathrobium (Coleoptera, Staphylinidae) from Yunnan Province, Southwest China. - Elytra, Tokyo 25 (2): 493-508.

Watanabe, Y. \& XiaO, N.-N. 2000: Seven new apterous Lathrobium (Coleoptera, Staphylinidae) from Yunnan, Southwest China. - In: AoKI, J.-I.; YIN, W.-Y. \& ImADATÉ, G. (eds), Taxonomical Studies on the Soil Fauna of Yunnan Province in Southwest China. Tokai University Press: 179-196. 